\title{
Host cell amplification of nutritional stress contributes to persistence in Chlamydia trachomatis
}

\author{
Nick D. Pokorzynski ${ }^{1,2}$ \& Rey A. Carabeo ${ }^{1 *}$
}

\begin{abstract}
${ }^{1}$ Department of Pathology and Microbiology, University of Nebraska Medical Center, Omaha, NE, USA
${ }^{2}$ Current affiliation: Department of Microbial Pathogenesis, Yale University School of Medicine, New Haven, CT, USA

*Correspondence: rey.carabeo@unmc.edu
\end{abstract}

\begin{abstract}
Persistence, a viable, but non-replicating state has been implicated in diseases caused by Chlamydia trachomatis. Multiple nutritional stressors produce a superficially similar "persistent" state, yet no systematic comparison has been made to determine their likeness. We employed host-pathogen dual RNA-sequencing under both iron- and tryptophan-starved conditions to gain insight into chlamydial persistence and identify contributions by the host cell. Analysis of the transcriptome of iron- or tryptophan-starved Chlamydia revealed a common "core" component and a stress-specific "accessory" subset. Despite the overall transcriptomic differences of host cells starved for either iron or tryptophan, both stressors induced persistence. A common metabolic consequence of the stressors was a reduction in intracellular GTP levels. Mizoribine inhibition of IMDPH1, which catalyzes the rate-limiting step in de novo guanine nucleotide synthesis reproduced to a similar extent GTP depletion, and inhibited chlamydial growth as expected for a pathogen that is auxotrophic for GTP. Thus, the reduction of guanine nucleotide synthesis manifests amplification of either iron or tryptophan starvation contributing to persistence. These findings illustrate that a nutritionally stressed host cell remains effective in arresting growth of Chlamydia by targeting metabolic pathways required by the pathogen.
\end{abstract}

\section{INTRODUCTION}

The dynamics of intracellular infection reflect the interaction of the pathogen and the host cell, with the outcome of the battle shaped by the competition between pathogen virulence and host counteractive measures (Prentice et al., 2007). A cytokine that tilts the balance towards the host is interferon-gamma (IFNg), the effects of which are amplified by the JAK/STAT signaling pathway to induce a varied collection of responsive genes, including several antimicrobial effectors (Shtrichman and Samuel, 2001). In turn, pathogens have evolved to acquire strategies that attenuate or neutralize IFNg (Finlay and McFadden, 2006). Interestingly, some of these anti-microbial activities could potentially compromise host cells in their ability to deal with infections. For example, differential regulation of iron acquisition and storage mechanisms designed to starve the pathogen of this metal would be expected to starve the host of iron (Abreu et al., 2020; Nairz et al., 2014). A similar scenario applies to tryptophan depletion mediated by the catabolizing enzyme indoleamine-2,3-dioxygenase (IDO1) (Byrne et al., 1986). While it starves intracellular pathogens for tryptophan, it concomitantly deprives the host of this essential amino acid. Here, we interrogate the response of the host cell subjected to models of nutrient starvation (e.g. iron starvation by chelation with 2,2-bipyridyl and tryptophan limitation via growth in tryptophan-depleted medium) typically used to simulate specific IFNg-responsive antimicrobial effectors. Specifically, we sought to determine if under such growth conditions the host cell is compromised in clearing the infection, and if the pathogen response reflects this compromised state.

A typical response of Chlamydia trachomatis (Ctr) to iron or tryptophan starvation is the establishment of "persistence". Chlamydiae are distinguished by a biphasic developmental cycle that interconverts an infectious, nonreplicative elementary body (EB) with a non-infectious, replicative reticulate body (RB) (AbdelRahman and Belland, 2005). Chlamydiae can disengage their normal developmental program and enter a persistent state in response to a wide array of stress (Panzetta et al., 2018; Wyrick, 2010), including antibiotic treatment (Skilton et al., 2009), amino acid starvation (Beatty et al., 1994; Belland et al., 2003; Hatch and Ouellette, 2020) or biometal limitation (Ardissone et al., 2020; Raulston, 1997; Thompson and Carabeo, 2011). Chlamydial persistence shares many hallmarks with conventional bacterial persistence: for instance, persistent Chlamydiae are re-activatable (Beatty et al., 1995) and tolerant to bactericidal antibiotics (PhillipsCampbell et al., 2014; Wyrick and Knight, 2004). Yet Chlamydia lack most of the suspected genetic determinants (e.g. TA modules, stringent response) implicated in conventional models of bacterial persistence (Eisenreich et al., 2021) and display unique traits that imply a more fundamental process. For example, chlamydial persistence appears homogeneous, rather than stochastic, as all organisms in a given inclusion typically adopt characteristic aberrant bacterial morphology (Beatty et al., 1993; Belland et al., 2003; Matsumoto and Manire, 1970).

The prevailing view is that persistence is the result of the accumulated effects of the stressor on the pathogen. 
For example, persistence resulting from iron starvation is thought to arise from the combined action of inactivating iron-dependent enzymes and the dysregulation of the ironresponsive regulon, both of which are expected to have pleiotropic effects on Chlamydia (Al-Younes et al., 2001; Raulston, 1997). Tryptophan starvation on the other hand is expected to reduce translation of proteins that are tryptophan-rich; and the resulting skewed proteome disrupts chlamydial growth and development (Ouellette et al., 2016). These are likely to be an oversimplification of the interaction between pathogen and host because the effects of the nutritional stress on the host cell, which itself deploys adaptive responses, is not considered. In other words, the nature of these adaptive responses might inform on the host cell priority, i.e. inhibit pathogen growth or survive the side effects of the anti-microbial effectors. It is also possible that these two priorities can coexist, and perhaps cooperate to clear infection effectively.

We therefore systematically compared tryptophanand iron-starved Ctr-infected epithelial cells via hostpathogen dual RNA sequencing (RNA-seq). We find that the morphological and developmental fate of Ctr is dependent on the nutritional insult applied, but that these outcomes are independent of the treatment regimen, implying that Ctr senses and actively initiates a persistent state. RNA-seq analysis of the transcriptomes of both the infected epithelial cell and Ctr under these conditions revealed that while the transcriptome of the infected host cell is distinct to each stress, the chlamydial transcriptome demonstrated a high level of conservation between conditions but maintains a subset of stress-specific differentially expressed (DE) "accessory" genes. In addition, we report that the nutrientdeprived host cell appears to enhance its anti-bacterial activity, starving Ctr of the essential nucleotide guanosine triphosphate (GTP). This was a common metabolic consequence of both iron- and tryptophan starvation of host cells, regardless of infection. The pathogen responded accordingly by up-regulating genes for GTP-dependent cofactor biosynthesis. Treatment of infected cells with mizoribine, a specific inhibitor of IMPDH1 reproduced both the growth defect and the chlamydial upregulation of riboflavin and folate biosynthesis genes. Together, these data support the view that a nutritionally stressed cell is not compromised in its ability to handle infection by an intracellular pathogen. That GTP depletion is a common metabolic consequence of the two stresses indicate that amplification of the primary stress could be an intrinsic property of host cells. This feature of the host cell should be considered as we build a more detailed picture of hostpathogen interactions using accepted methods of inducing nutritional stress in intracellular pathogens.

\section{RESULTS}

\section{Alternate models of chlamydial persistence produce discernable phenotypic differences.}

To establish models of chlamydial persistence, we subjected Ctr-infected HeLa cells to iron starvation, by treatment with the membrane permeable iron chelator 2,2bipyridyl (BPD) (Thompson and Carabeo, 2011), or tryptophan starvation, by culturing in a defined medium lacking tryptophan (TRP) (Pokorzynski et al., 2020, 2019). We applied two treatment regimens (Figure 1A), one which started at the time of infection and continued for 24 hours (h; BPD24, TRP24), reflecting established models of chlamydial persistence, or one that began at $8 \mathrm{~h}$ postinfection (hpi) and continued for 16h (BPD16, TRP16), thereby allowing $\mathrm{Ctr}$ to establish a productive infection and differentiate into the replicative RB state prior to nutrient starvation. We then assayed several physiological hallmarks of chlamydial persistence to identify differences between nutrient stress or treatment regimen. We first assayed chlamydial morphology by immunofluorescent confocal microscopy (Figure 1B). In comparison to the untreated control (UTD24), all treatments produced qualitatively smaller inclusions, implying inhibited growth. We observed clear morphological differences between BPD and TRP, with BPD inclusions being occupied by aberrantly enlarged organisms while TRP inclusions displayed an "indiscrete" morphology, obscuring the observation of individual bacteria. We then analyzed genome copy number under each condition and observed that while all treatments significantly reduced genome equivalents compared to UTD24, no differences were statistically distinguishable between BPD and TRP (Figure 1C). In contrast, we found that TRP was more permissive to the generation of infectious progeny (Figure 1D), as BPD reduced recoverable inclusion forming units (IFUs) below the calculated limit of detection. Thus, while a comparable number of genome equivalents, and by extension chlamydial organisms, exist under each treatment condition, whether those chlamydiae can complete their developmental cycle is influenced by the model of persistence employed.

We then analyzed the expression of a panel of chlamydial genes commonly used to indicate developmental dysregulation by reverse transcription quantitative PCR (RTqPCR): trpRBA, ytgA, omcB and ompA (Figure 1E). Consistent with previous reports, we observed that the tryptophan salvage operon, $\operatorname{trpRBA}$, was significantly upregulated in both BPD and TRP, though TRP increased trpRBA expression significantly compared to BPD. This is due to dual regulation by the tryptophan-dependent transcriptional repressor TrpR and the iron- and tryptophandependent repressor YtgR (Pokorzynski et al., 2020, 2019). In contrast, the expression of the periplasmic iron-binding protein $y \operatorname{tg} A$, another gene regulated by $\mathrm{YtgR}$ (Thompson et al., 2012), was not significantly altered by any treatment condition, despite prior reports of its iron- and tryptophandependent induction (Pokorzynski et al., 2020; Thompson and Carabeo, 2011). Here, we utilized a transcriptomebased normalization method (see Materials and Methods, Figure 1 - Supplementary Text, Figure 1 - Figure Supplement 1), rather than normalizing to genome equivalents. This indicates that while YtgR regulation of $\operatorname{trpRBA}$ serves to increase the expression of the operon relative to the total transcriptome, YtgR regulation of $y \operatorname{tg} A$ maintains a constant proportion of transcripts across various developmental or nutritional conditions. We confirm that the expression of $o m c B$, a cysteine-rich outer membrane protein associated with differentiation to the EB stage and common 
A
Infect
$8 \mathrm{hpi}+16 \mathrm{~h}$
(MOI 5)
conditions
Collect
samples

B DAPI/cHsp60
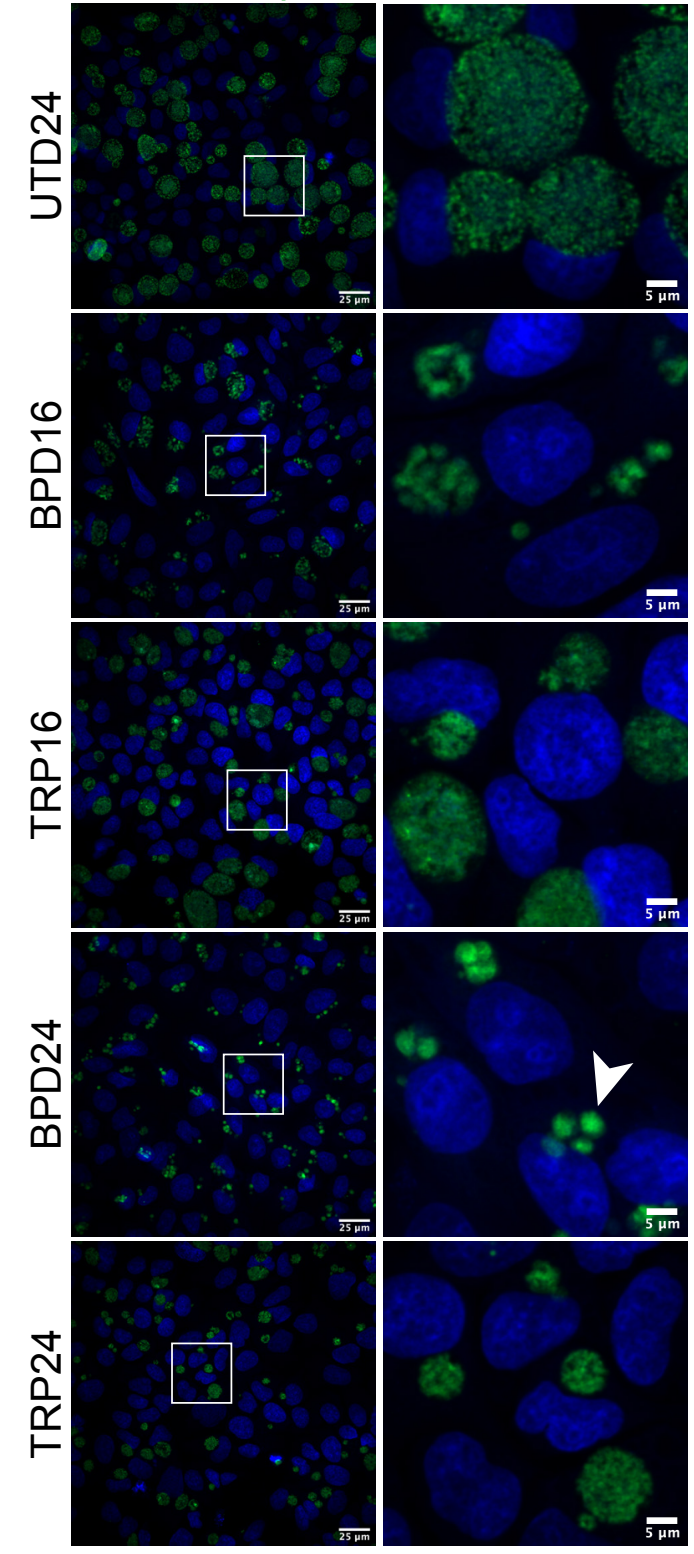

Inset

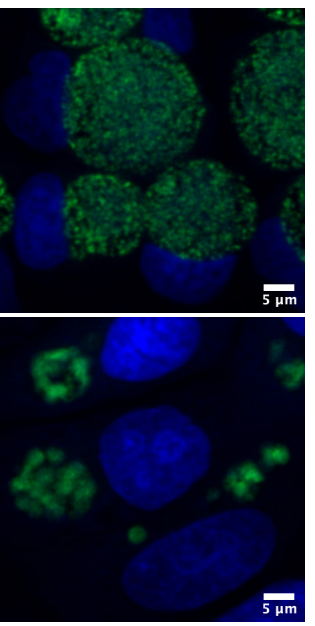

=

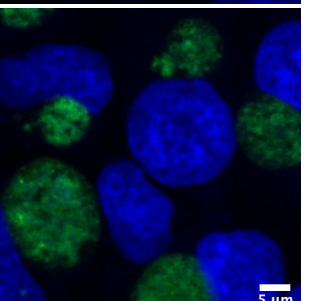

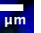

$5 \mu \mathrm{m}$

E

C
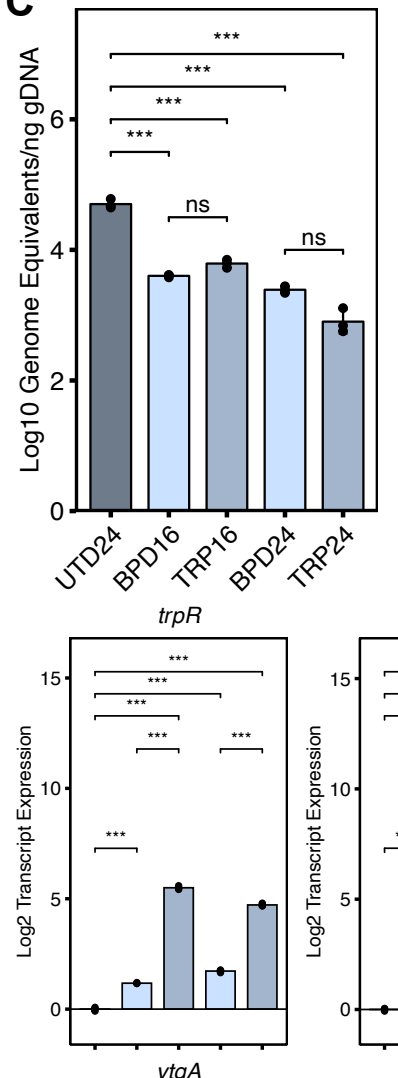

$y \operatorname{tg} A$

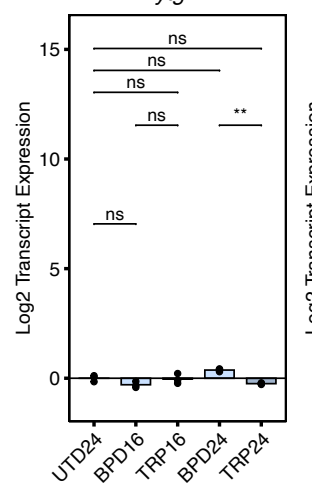

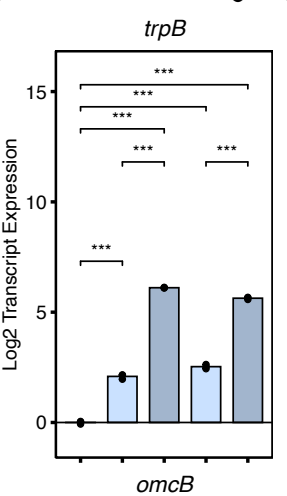

Figure 1. Alternative models of chlamydial persistence are not phenotypically identical. (A) Diagram depicting the experimental design used throughout this study, where 24h treatment conditions (UTD24, BPD24, TRP24) begin at the time of infection, and 16h treatments begin at 8 hours post-infection (BPD16, TRP16). (B) Immunofluorescent confocal microscopic analysis of chlamydial morphology under various models of chlamydial persistence. Micrographs are representative of at least three independent biological replicates $(\mathrm{N}=3)$. Chlamydial organisms were detected by immunostaining against the cytosolic Hsp60 homologs, GroEL_1GroEL_3. Nuclei were detected by staining with DAPI. Arrowheads indicate aberrantly enlarged bacteria. (C) Determination of genome equivalents by quantitative PCR against the euo locus under the various persistence models. (D) Measurement of infectious progeny generation during nutritional stress in a reinfection assay. Dotted line indicates calculated limit of detection for the assay. ND $=$ not detected. (E) Gene expression profiles for various nutritionally- or developmentally-regulated chlamydial genes. All plots represent the mean and standard deviation of three independent biological replicates $(N=3)$. Statistical significance in all panels was determined by one-way ANOVA followed by Tukey's post-hoc test of honestly significant differences (two-tailed). ${ }^{*}=p<0.05,{ }^{* *}=p<0.01,{ }^{* * *}=$ $p<0.001, \mathrm{~ns}=$ not significant. 
bioRxiv preprint doi: https://doi.org/10.1101/2021.08.14.456350; this version posted August 15, 2021. The copyright holder for this preprint (which was not certified by peer review) is the author/funder, who has granted bioRxiv a license to display the preprint in perpetuity. It is made available under aCC-BY 4.0 International license.

biomarker of persistence, is down-regulated by nutritional stress, as is the expression of ompA, the major outer membrane protein in Ctr. While some statistically distinguishable differences exist between stress conditions, we find that these are differences in magnitude but not the directionality of expression. We conclude that while both stimuli induce physiological changes characteristic of persistence, iron starvation has a more profound effect on chlamydial physiology than media-defined tryptophan starvation. While more extreme treatment conditions may reveal a higher degree of concordance between the physiological endpoints of various persistence models, our results nevertheless underscore that different persistence models produce varied results.

\section{Chlamydia initiates a common transcriptional program in response to distinct nutritional stressors.}

To characterize the chlamydial response systematically and unbiasedly to both tryptophan and iron starvation, we turned to dual RNA-seq to elucidate the persistent chlamydial transcriptome in relation to the transcriptional response of the infected host cell. Our experiment was designed to capture the presumably small fraction of chlamydial transcripts produced in persistently infected HeLa cells, and we accordingly used a multiplicity of infection (MOI) of five for each condition. In agreement with recent reports, we recovered high levels of chlamydial transcripts in each library (Hayward et al., 2021), with no fewer than $7.5 \times 10^{6}$ mapped reads under any condition. We also note that across replicates, no more than $0.01 \%$ of the total library mapped to the chlamydial reference genome in any mock-
A

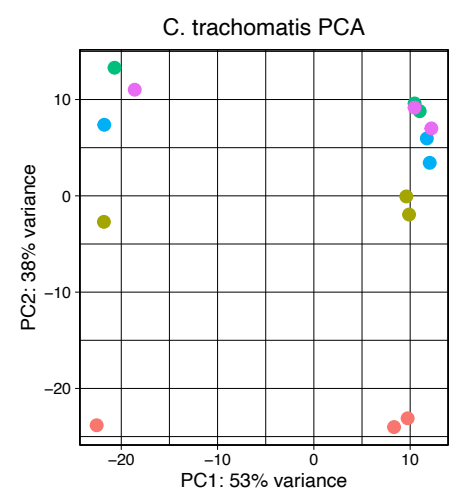

C
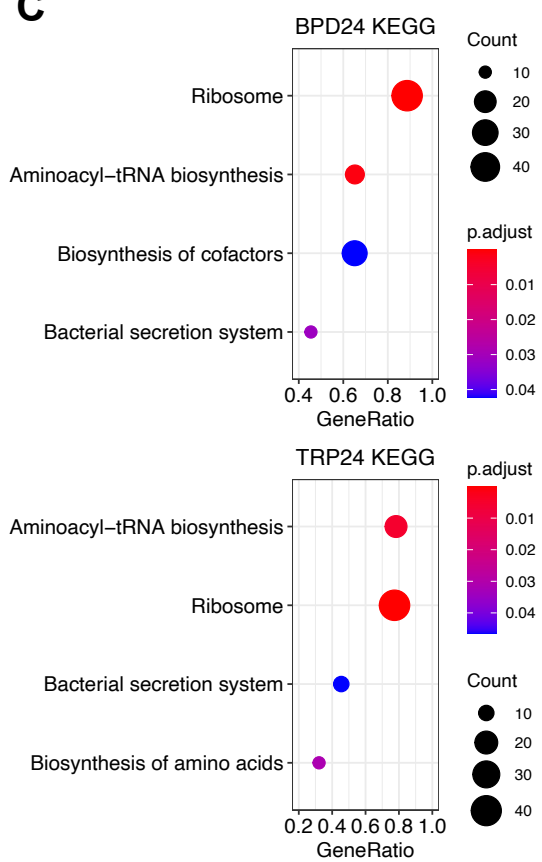

B

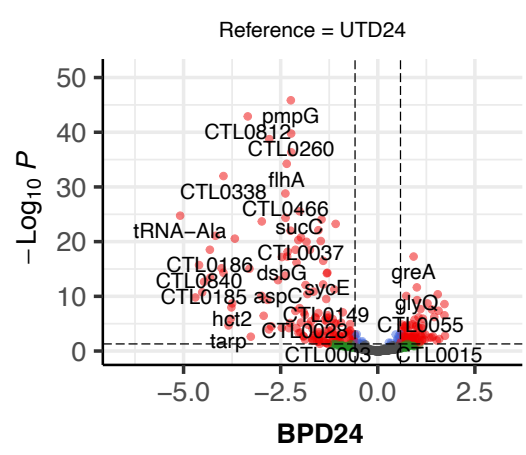

Reference $=$ UTD24

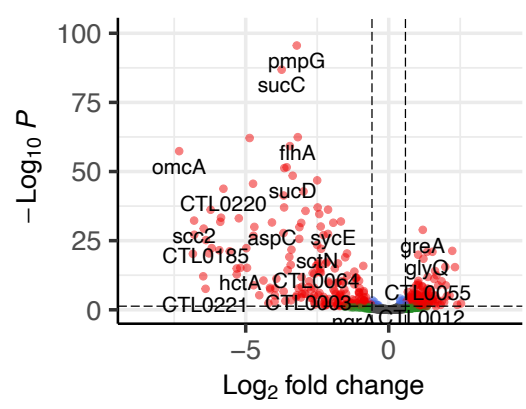

total $=970$ variables

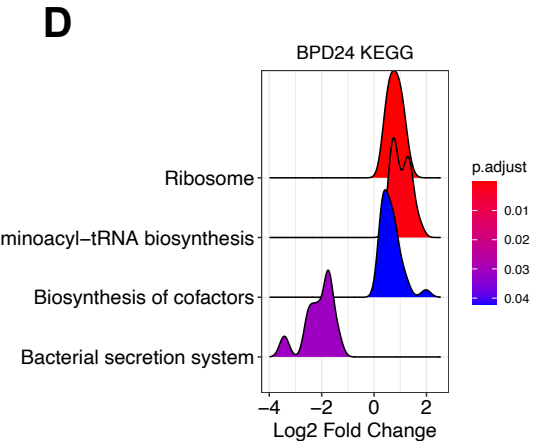

TRP16
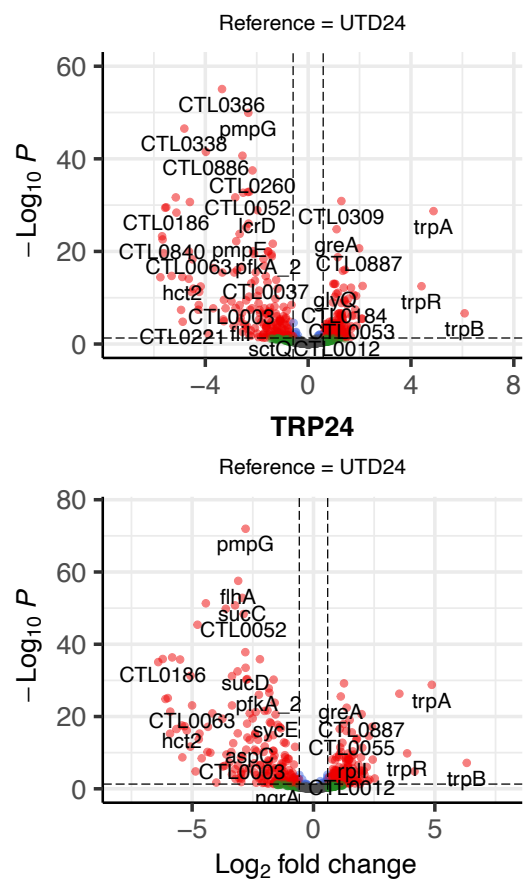

total $=970$ variables

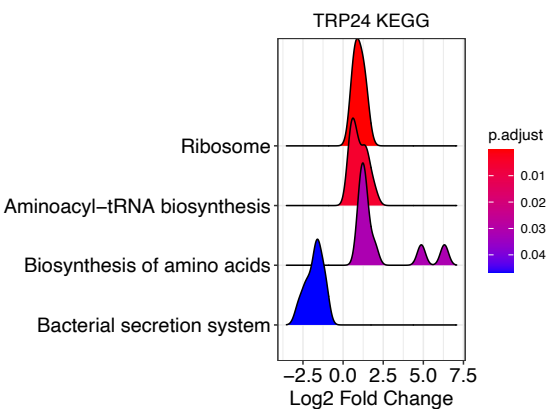

Figure 2. The persistent chlamydial transcriptome is broadly conserved across conditions. (A) Principal component analysis (PCA) of the chlamydial transcriptomes derived from the various nutrient-deprived conditions. All data are from three independent biological replicates $(\mathrm{N}=3)$. (B) Volcano plots of the differentially expressed (DE) genes under each persistence-inducing condition (adjusted $p$ value $<0.05$, |Fold change $\mid>1.5)$. Red $=\mathrm{DE}$, blue $=p<0.05,|\mathrm{FC}|<1.5$, green $=p>0.05,|\mathrm{FC}|>1.5$, grey $=p>0.05,|\mathrm{FC}|<1.5 .(\mathbf{C})$ Dot plots for enriched pathways identified by clusterProfiler in BPD24 and TRP24. Dot size reflects the number of genes enriched in the pathway and dot color indicates the statistical significance of pathway enrichment. (D) Ridge plots for enriched pathways identified by clusterProfiler in BPD24 and TRP24. Ridges represent normalized density of genes plotted against their Log2 fold change. Ridge color reflects statistical significance of pathway enrichment. 
infected sample, indicating a negligible influence of crossaligned reads in our samples.

Analysis of our RNA-seq datasets revealed that the transcriptional response of $\mathrm{Ctr}$ is largely conserved across conditions. Complete details of the differential expression analysis can be found in Figure 2 - Supplemental Data 1. Principal component analysis of the variation between chlamydial transcriptomes demonstrated clustering of all treated conditions, albeit with variation between replicates (Figure 2A). Nevertheless, this indicated that the chlamydial transcriptome associated with different stressors and treatment regimens is highly similar. This is further emphasized by surveying the landscape of statistically significant DE genes (adjusted $p$-value $<0.05,|F C|>1.5$ ), where we observe all conditions produce a more significantly down-regulated than up-regulated set of genes (Figure 2B). Notably, we observe consistently strong downregulation of virulence-associated genes such as the polymorphic outer membrane protein, pmpG (Becker and Hegemann, 2014; Carrasco et al., 2011), and the histonelike, nucleoid condensing genes hctA and hctB (hct2) (Barry III et al., 1993; Belland et al., 2003; Hackstadt et al., 1991). Furthermore, we note that RNA-seq reproduces the substantial up-regulation of $\operatorname{trpRBA}$ in TRP as observed by RT-qPCR (see Figure 1E). Thus, our RNA-seq data recapitulates expected trends based on previous gene expression studies in Ctr.

Next, we subjected the sets of DE genes from each condition to KEGG pathway gene set enrichment analysis (GSEA). Due to the gross similarity between treatment regimens, we limit the analysis here to BPD24 and TRP24 but provide complete details of the analysis for each condition in Figure 2 - Supplemental Data 2. Among the significantly enriched pathways identified, we observed a high level of agreement between treatments, with the pathways "Ribosome" (ctb03010) and "Aminoacyl-tRNA biosynthesis" (ctb00970) significantly enriched in all conditions and "Bacterial secretion system" (ctb03070) significantly enriched in three of four conditions (Figure 2C). Consistent with previous studies, "Ribosome" and "Aminoacyl-tRNA biosynthesis" pathways are activated, while the virulence-associated "Bacterial secretion system" pathway is suppressed (Figure 2D) (Belland et al., 2003). Interestingly, GSEA also revealed the unique enrichment of categories specific to a given treatment. BPD24 significantly activates the "Biosynthesis of cofactors" (ctb01240) pathway, whereas TRP24 results in significant enrichment of the "Biosynthesis of amino acids" (ctb01230) pathway (Figure 2, C and D). While the enrichment of "Biosynthesis of amino acids" is likely driven by the substantial upregulation of the trpRBA operon in TRP24, the identification of functionally unique pathways under both nutrient conditions implies that while the overarching transcriptome may be similar, Ctr possess the ability to tailor their transcriptional response to a given stress.

\section{The "core" persistent transcriptome is decorated by differentially expressed "accessory" genes unique to each nutritional condition.}

Characterization of the chlamydial transcriptome across multiple nutritional conditions revealed a conserved, "core" persistent transcriptome in Ctr. This core persistent transcriptome consisted of $30.52 \%$ of the up-regulated genes (Figure $3 \mathrm{~A}$ ) and $56.7 \%$ of the down-regulated genes across conditions (Figure 3B). Network maps were generated from the core DE up- or down-regulated genes obtained from BPD24 and TRP24 (Figure 3, C and D). The full list of core DE genes can be found in Figure 3 Supplemental Data 1. Within the up-regulated set of genes, a highly interconnected node emerged representing several ribosomal subunit and translation adaptor genes (Figure $3 \mathrm{C}$ ), consistent with previous reports on the persistent chlamydial transcriptome (Belland et al., 2003). However, it is unclear if this up-regulation leads to increased translational activity (Ouellette et al., 2006). Rather, this may reflect a preparation for reactivation such that translation can rapidly resume once conditions improve. In the downregulated set of core genes, a more disconnected network was produced, though distinct nodes emerged, including virulence genes (e.g. tarp, hctA, pmpE, omcB) and type III secretion system components (e.g. sctN, sctQ, sctU) (Figure 3D). These data collectively confirm previous findings on chlamydial persistence, but provide a more detailed view of the conserved transcriptional stress response in Ctr.

Despite the high degree of transcriptional conservation, Ctr maintained many DE "accessory" genes that were treatment-specific (Figure 3, A and B). Interestingly, a higher proportion of the up-regulated genes were unique, with $10.33 \%$ and $12.21 \%$ of all up-regulated genes being unique to BPD24 and TRP24, respectively (Figure $3 \mathrm{~A}$ ), compared to only $4.91 \%$ of down-regulated genes for both conditions (Figure 3B). Network plots were generated for the uniquely up-regulated genes for BPD and TRP (Figure 3, E and F). The complete list of up- and downregulated accessory genes can be found in Figure 3 Supplemental Data 2. Among the recognized genes, few associations were derived for BPD, though a small node emerged apparently related to energy transduction by ATP synthase (Figure 3E). In contrast, multiple small nodes emerged in TRP, including one for inclusion membrane proteins (Incs; incC, incB, ct228/ctl0480), transcriptional regulators ( $n r d R$, trpR, euo) and a node comprising translation (phe T, rps T), transcription $(r p o D)$ and genome replication (gyrB, gyrA2) components (Figure 3F). We selected two accessory genes from each condition to confirm their differential expression by RT-qPCR: for BPD, we selected the peptidoglycan (PG) amidase, amiA, and the beta subunit of ATP synthase, atpB (ct/0559), and for TRP we selected the diaminopimelate aminotransferase dapL and the tyrosine/tryptophan amino acid transporter tyrP (tyr $P_{-}$1). We confirmed that amiA was uniquely up-regulated in BPD24 and that tyrP was significantly up-regulated in TRP24 relative to BPD24, however dapL was significantly up-regulated in BPD24 compared to TRP24 and atpB expression was up-regulated in both conditions compared to UTD24 but not significantly different between conditions (Figure 3 - Figure Supplement 1). Thus, we conclude that PG turnover is uniquely up-regulated by BPD treatment which may explain the distinct bacterial morphology observed under this condition (see Figure 1B) (Brockett and Liechti, 2021). 
bioRxiv preprint doi: https://doi.org/10.1101/2021.08.14.456350; this version posted August 15, 2021. The copyright holder for this preprint (which was not certified by peer review) is the author/funder, who has granted bioRxiv a license to display the preprint in perpetuity. It is made available under aCC-BY 4.0 International license.

A

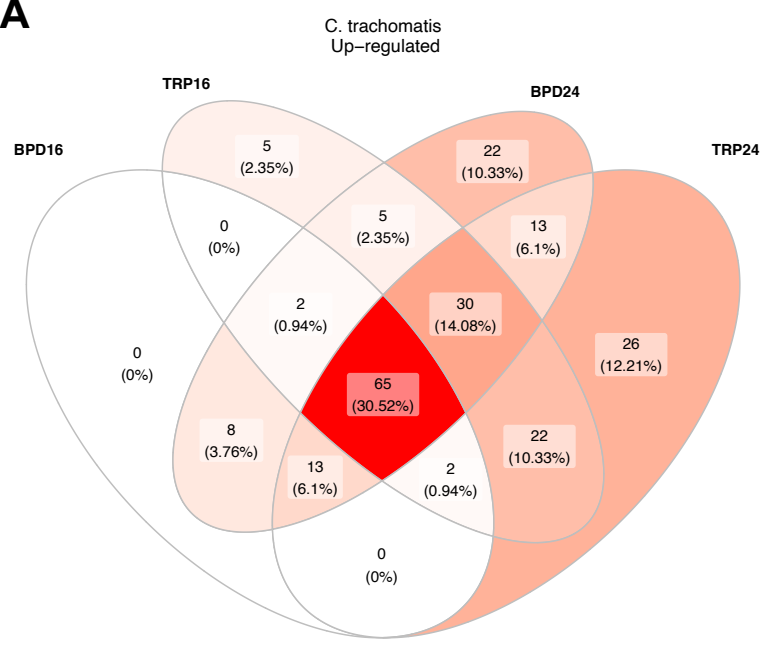

C

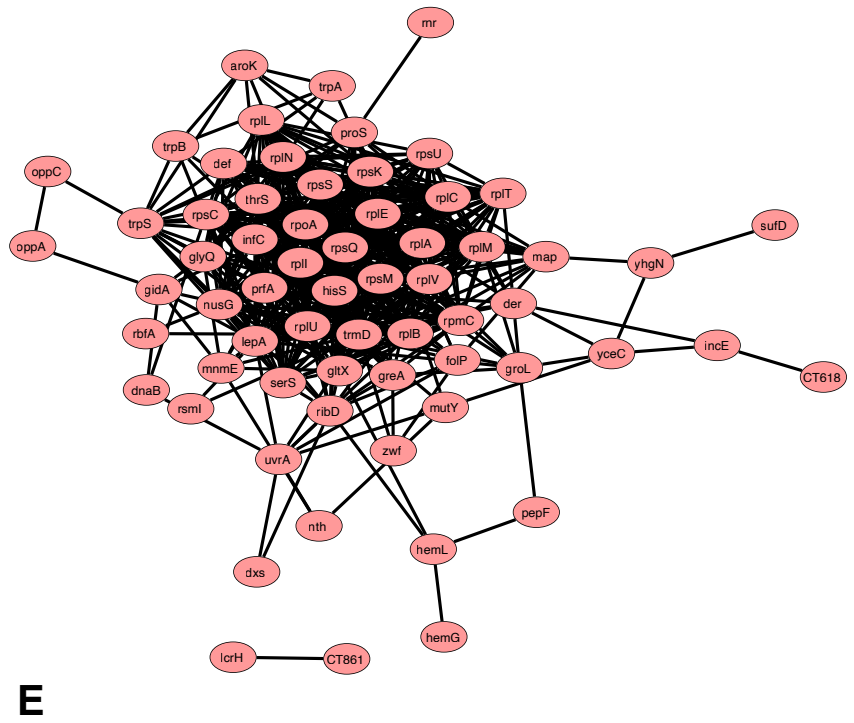

BPD "Accessory" Up-regulated

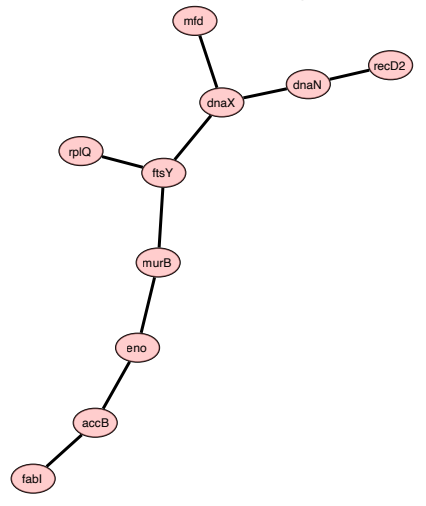
B $\quad \begin{gathered}\text { C.trachomatis } \\ \text { Down-regualeded }\end{gathered}$

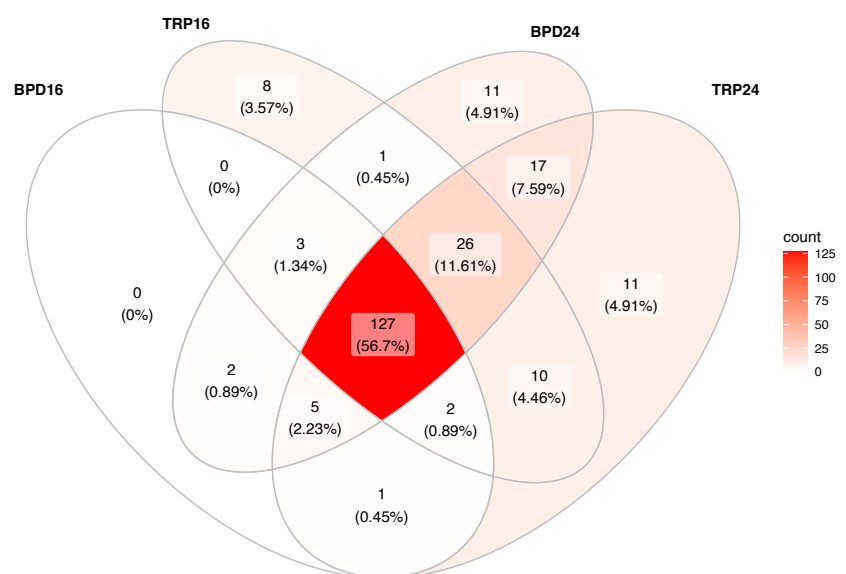

D

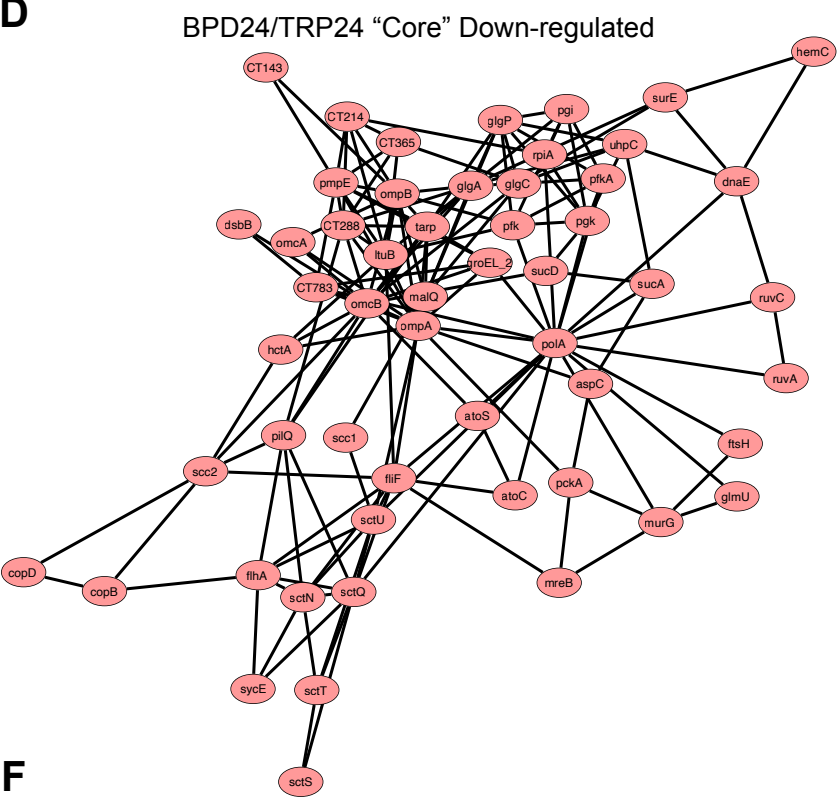

TRP "Accessory" Up-regulated

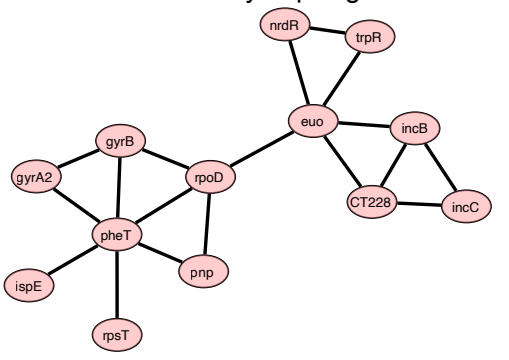

$\int_{\text {dapB }}^{\text {dapL }}$<smiles>[C-]C=CC=[Ge]</smiles>

Figure 3. The core persistent chlamydial transcriptome is decorated by unique accessory genes in each condition. (A) Venn diagram of all differentially up-regulated genes across the various nutritional conditions. Color shading reflects the relative number of genes in each cross-section of the Venn diagram. (B) Same as in (A) for all differentially down-regulated genes. (C) Network plot of the core up-regulated genes in BPD24 and TRP24. Network consists of those genes that were recognized by the STRING-db server. (D) Same as in (C) for the core down-regulated genes. (E) Network plot of the up-regulated accessory genes across BPD conditions. Network consists of those genes recognized by the STRING-db server. (F) Same as in (E) for the TRP conditions. 
The transcriptional response of the infected epithelial cell is dependent on the nutritional condition.

We hypothesized that instances of unique transcriptional responses by Ctr could be correlated with specific variations in the transcriptional responses of the infected epithelial cell. Dual RNA-seq produced HeLa transcriptomes with no fewer than $3.3 \times 10^{7}$ mapped reads in any condition. We conducted a similar analysis for the host cell transcriptomes as was performed on the chlamydial transcriptomes. Principal component analysis of the HeLa transcriptomes revealed that, unlike Ctr, clustering was dependent on the treatment condition applied, with BPD forming a distinct cluster and TRP clustering with UTD24 (Figure 4A). All infected conditions clustered distinctly compared to the mockinfected control group (Mock). Subsequent analysis of differential gene expression (adjusted $p$-value $<0.05,|F C|>$ 2) was performed by analyzing UTD24 in reference to Mock, whereas all nutrient-starved samples were analyzed in reference to UTD24 to account for the influence of infection. Complete details of the differential expression analysis can be found in Figure 4 - Supplemental Data 1. We observed that compared to UTD24, all treatment conditions altered the global transcriptional profile, resulting in a more significantly down-regulated portion of the $\mathrm{DE}$ genes (Figure 4B). Whereas UTD24 resulted in a down-regulated set of 145 genes compared to Mock, no fewer than 630 genes were down-regulated under any nutrient-deprived condition, when compared to UTD24 (Figure 4 - Supplemental Data 1). We note the significant up-regulation of genes previously identified to respond to acute and persistent chlamydial infection, such as the antiviral protein OASL, in UTD24, TRP16 and TRP24 (Eickhoff et al., 2007). Having accounted for differentially expressed genes due to infection, the remaining differences in gene expression could be assigned confidently to the host response to nutritional stress or unique activities of persistent chlamydiae.

Next, we performed GSEA to identify differentially regulated pathways between conditions. Due to the similarity between treatment regimens (Figure 4A), here we display only the results from the analysis of the $24 \mathrm{~h}$ conditions but results for all conditions are provided in Figure 4 - Supplemental Data 2. We sorted pathways based on their enrichment score and plotted the results for the 15 most enriched pathways (Figure 4, C and D). We found that both BPD24 and TRP24 shared with UTD24 the enrichment of pathways related to infection, but also displayed uniquely enriched pathways - most notably in BPD24. The most enriched pathways in BPD24 comprised various categories, such as "Focal adhesion" (hsa04510), "PI3K-Akt signaling pathway" (hsa04151) and "Calcium signaling pathway" (hsa04020) (Figure 4C). We next inferred relatedness of the various enriched pathways by generating enrichment network maps for each condition (Figure 4D). We find that both UTD24 and TRP24 produced highly interconnected networks that form nodes related to the response to infection. In contrast, BPD24 produced a disconnected network, indicating functionally disjointed iron-responsive biological processes were induced under this condition. These data suggest that intracellular bacteria such as Ctr will encounter highly disparate host cell responses during nutritional stress, which we expect to have varying influences on the growth and development of resident chlamydiae.

\section{Suppression of host cell purine metabolism is reflected by the induction of GTP-dependent cofactor biosynthesis in persistent chlamydiae.}

The distinct transcriptional profiles of the infected host cell prompted further investigation into the relevance of functional pathways downstream of the primary (i.e. iron or tryptophan starvation) stresses. We extended our analysis of the HeLa GSEA data to include significantly suppressed pathways, which we found to differ between TRP and BPD. Suppressed pathways uniquely associated with BPD24 (Figure 5A, Figure 4 - Supplemental Data 2), included "Purine metabolism" (hsa00230), which was intriguing given that Ctr is auxotrophic for GTP (McClarty and Fan, 1993; Tipples and McClarty, 1993). In addition to DNA replication, transcription, and translation, GTP is also an essential substrate for chlamydial riboflavin and tetrahydrofolate (THF) biosynthesis (Adams et al., 2014). Because these two pathways fall within the broader "Biosynthesis of cofactors" pathway identified as significantly enriched by Ctr in BPD24 (Figure 2, C and D), we hypothesized that this enrichment is linked to the suppression of host GTP biosynthesis. We extracted the expression data for both the host and chlamydial pathways from the RNA-seq datasets for the BPD24 and TRP24 conditions and observed that host purine metabolism was markedly down-regulated transcriptionally in BPD24 compared to TRP24, particularly along the biosynthetic arm leading from ribose-5-phosphate to inosine monophosphate (Figure 5 - Figure Supplement 1, A and B).

In Figure 5B and Figure 5C, we depict the chlamydial riboflavin and THF biosynthetic pathways, simplified for clarity, with color-coded expression data for each gene annotated in the pathway. We then qualitatively compared the normalized expression of the two pathways between BPD24 and TRP24 to identify genes that were differentially regulated between the conditions. Genes within the riboflavin and THF biosynthetic pathways are broadly up-regulated in both BPD24 and TRP24, though differences exist in key genes. For example, the promiscuous enzyme $\operatorname{trpC}(\operatorname{trp} F)$, which shunts the product of the ribA GTP cyclohydrolase towards THF biosynthesis (Adams et al., 2014), appears differentially regulated between the BPD24 and TRP24 conditions (Figure 5C). Thus, the pathway-level identification of suppressed GTP biosynthesis in the host under BPD24 correlated with distinct gene expression patterns in the iron-starved chlamydiae. We therefore hypothesized that the reduction of GTP levels could be "sensed" by Ctr, yielding increased expression of genes involved in the GTP-requiring riboflavin and tetrahydrofolate biosynthetic pathways (Figure 5D). We note the intriguing finding, however, that both the riboflavin and THF biosynthetic pathways were generally upregulated in TRP24 (Figure 5, B and C), despite a less pronounced effect on the expression of the host purine metabolism pathway under this condition (Figure 5 - Supplemental Figure 1B). Given that pathway level analysis of gene expression is insufficient to infer actual alterations to metabolism, we addressed this apparent inconsistency with targeted pharmacological and biochemical assays. 
bioRxiv preprint doi: https://doi.org/10.1101/2021.08.14.456350; this version posted August 15, 2021. The copyright holder for this preprint (which was not certified by peer review) is the author/funder, who has granted bioRxiv a license to display the preprint in perpetuity. It is made available under aCC-BY 4.0 International license.

A

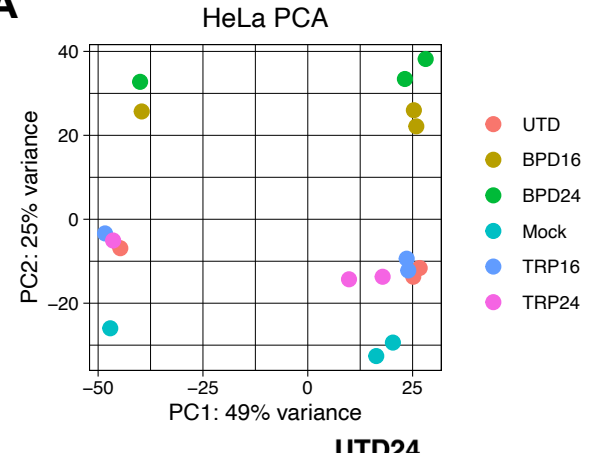

UTD24

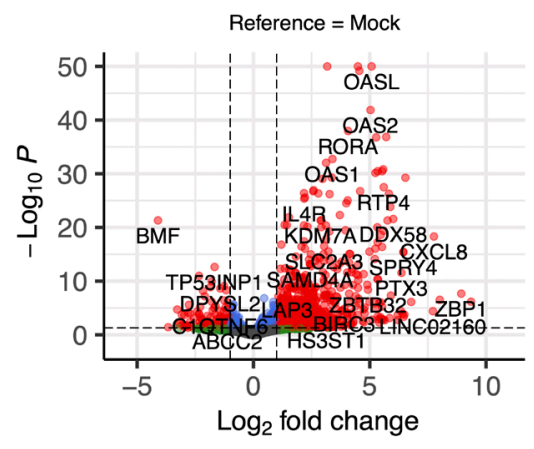

C

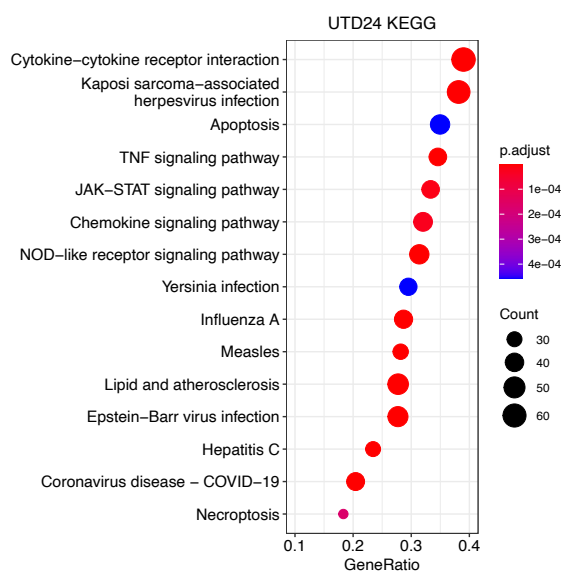

D
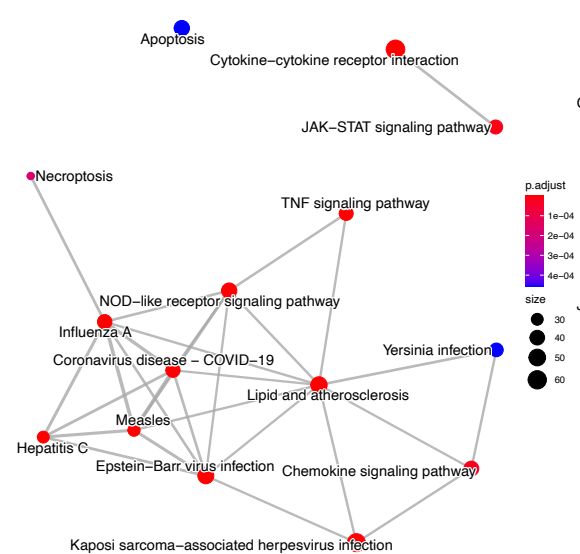

B
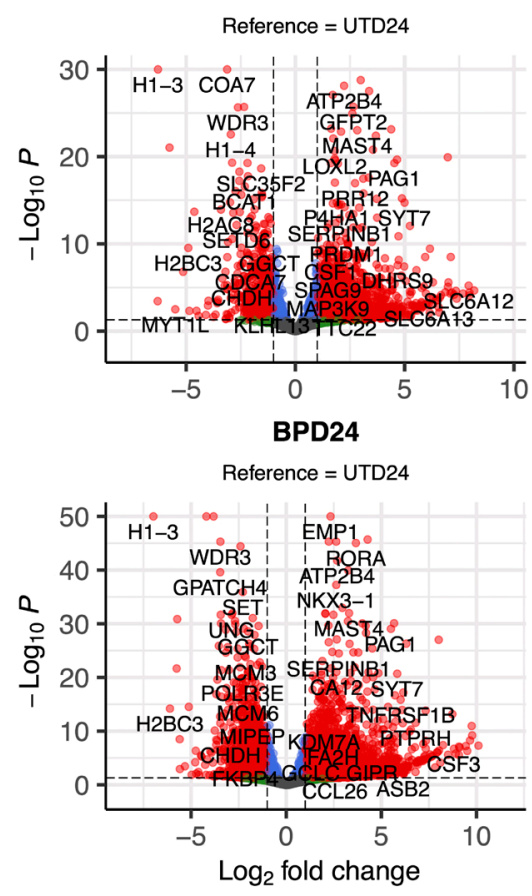

total $=\mathbf{2 8 7 1 5}$ variables

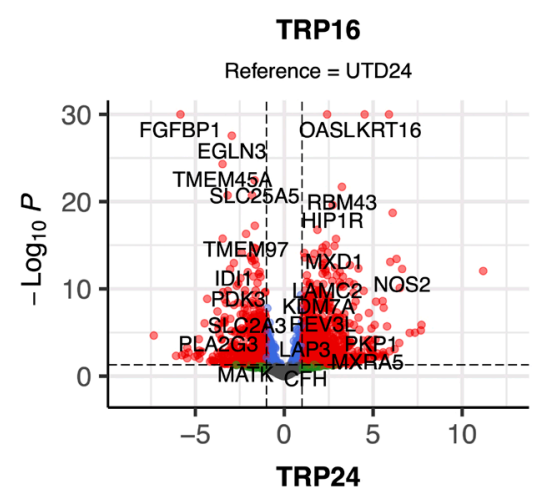

TRP24

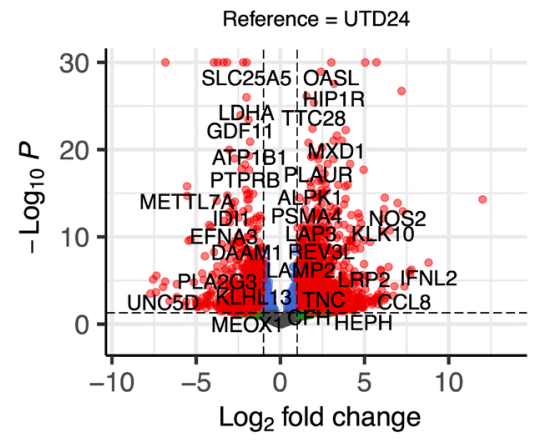

total $=28715$ variables

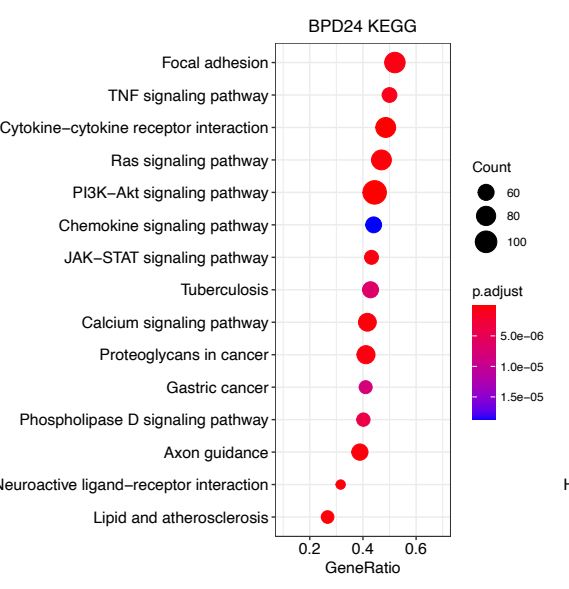

BPD24

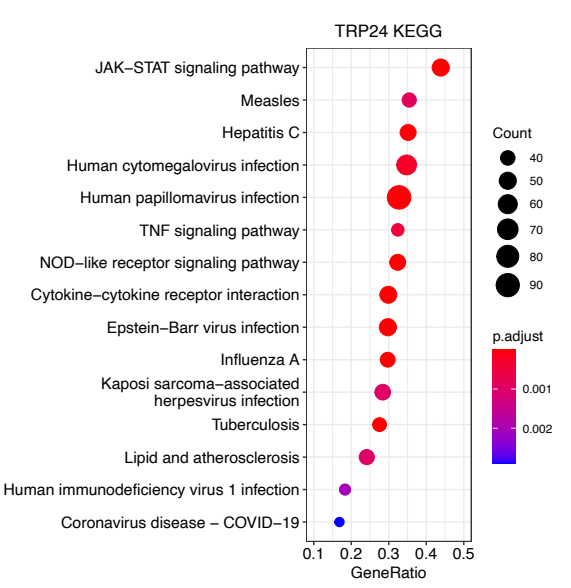

TRP24

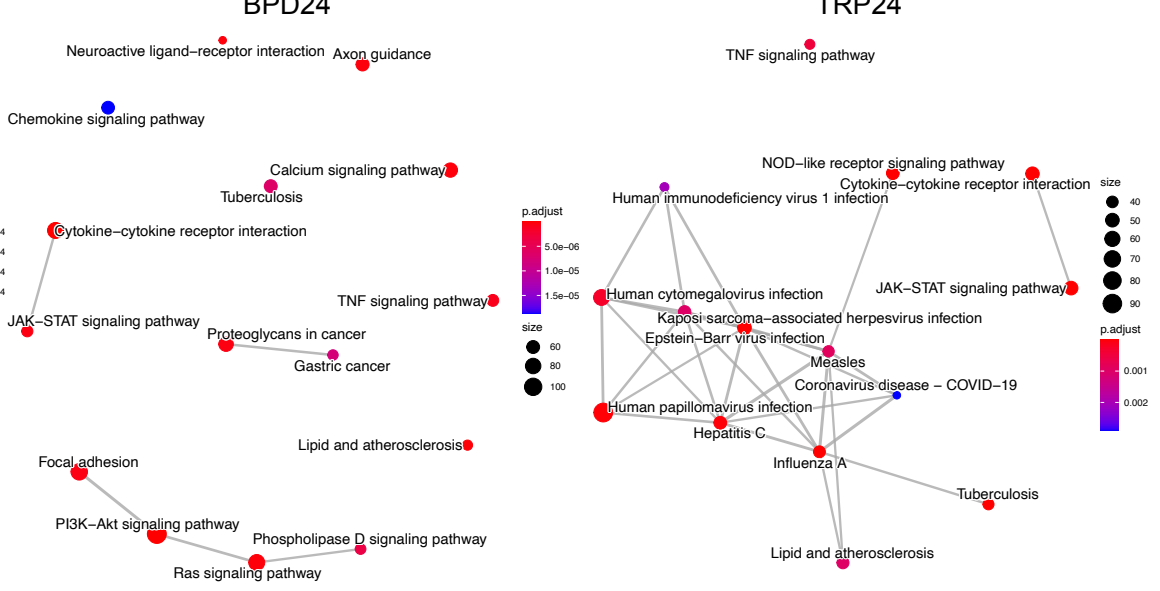

Figure 4. The infected host cell transcriptome differs between models of chlamydial persistence. (A) Principal component analysis (PCA) of the HeLa transcriptomes derived from the various experimental conditions. All data are $N=3$. (B) Volcano plots of the differentially expressed (DE) genes under each persistence-inducing condition (adjusted $p$-value $<0.05$, |Fold change $>2.0$ ). Note that UTD24 is relative to the mock-infected condition (Mock) whereas all other conditions are relative to UTD24. Red $=\mathrm{DE}$, blue $=p<$ $0.05,|\mathrm{FC}|<2.0$, green $=p>0.05,|\mathrm{FC}|>2.0$, grey $=p>0.05,|\mathrm{FC}|<2.0$. 
bioRxiv preprint doi: https://doi.org/10.1101/2021.08.14.456350; this version posted August 15, 2021. The copyright holder for this preprint (which was not certified by peer review) is the author/funder, who has granted bioRxiv a license to display the preprint in perpetuity. It is made available under aCC-BY 4.0 International license.

A
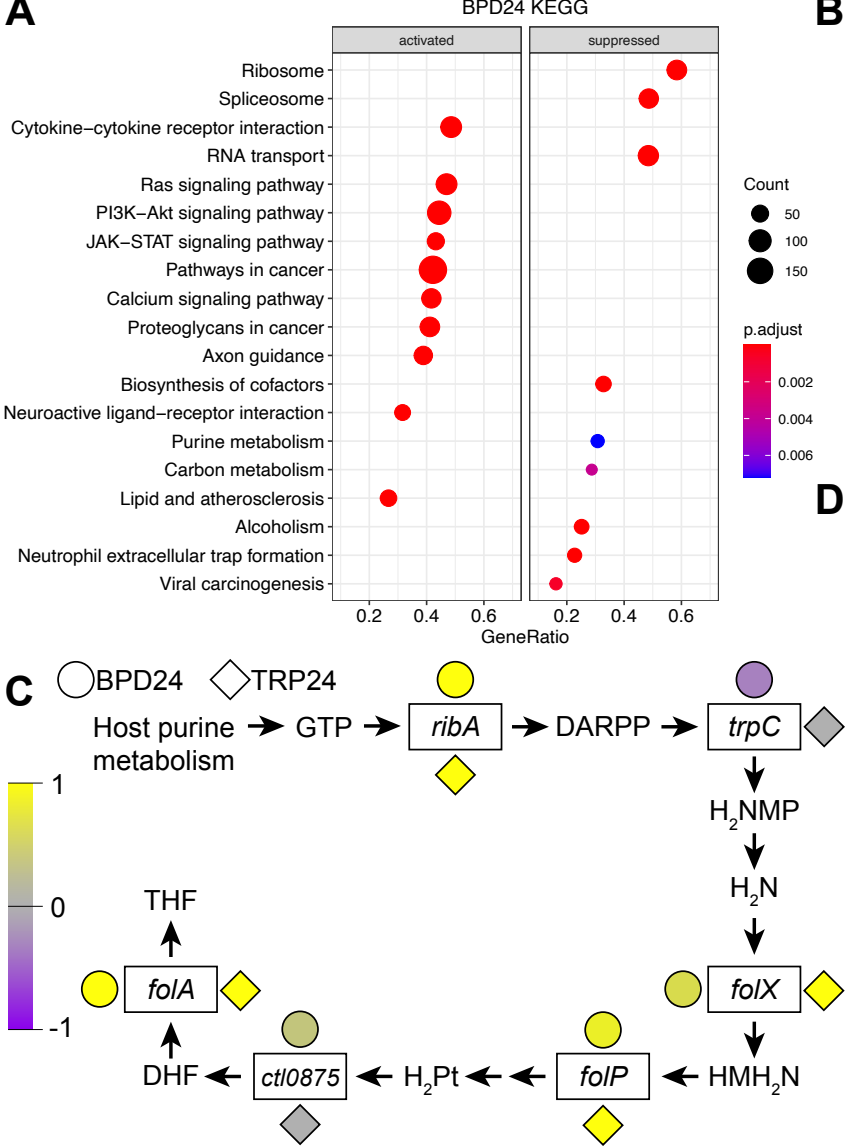

B
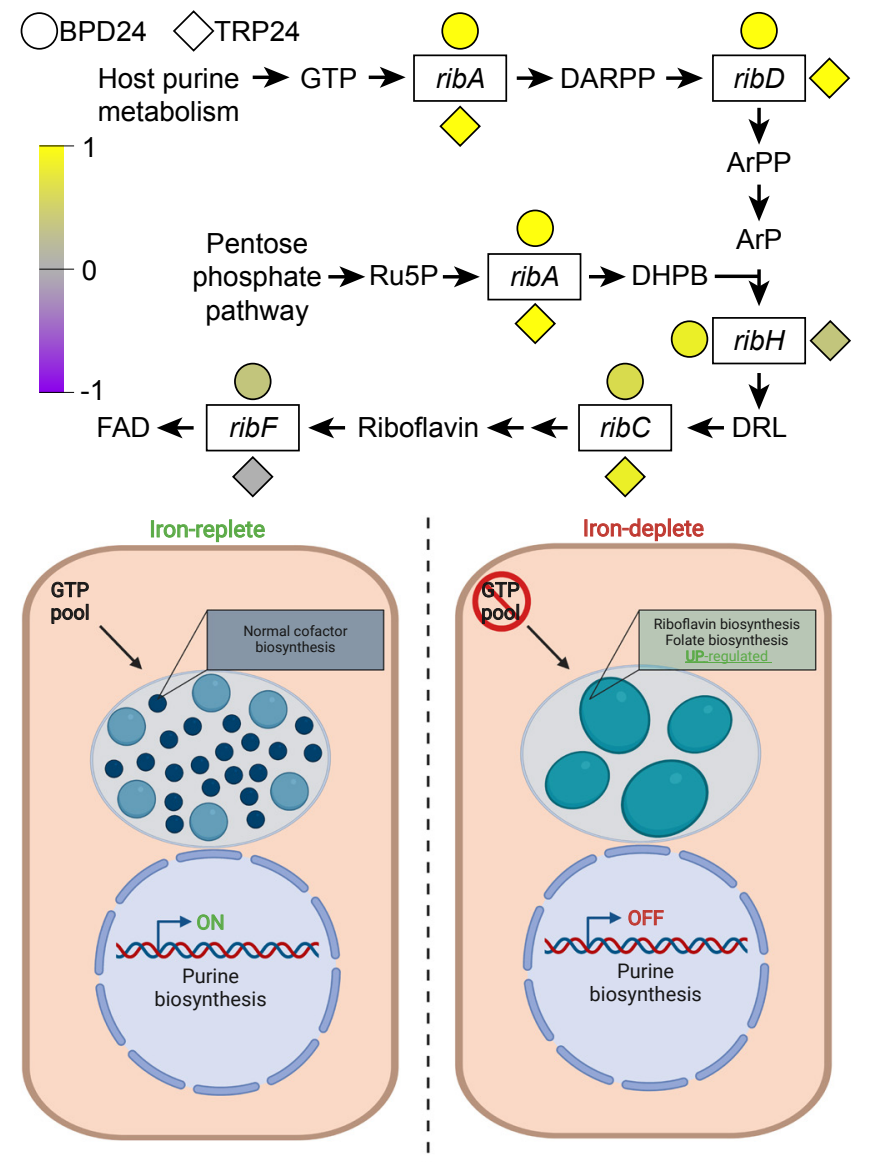

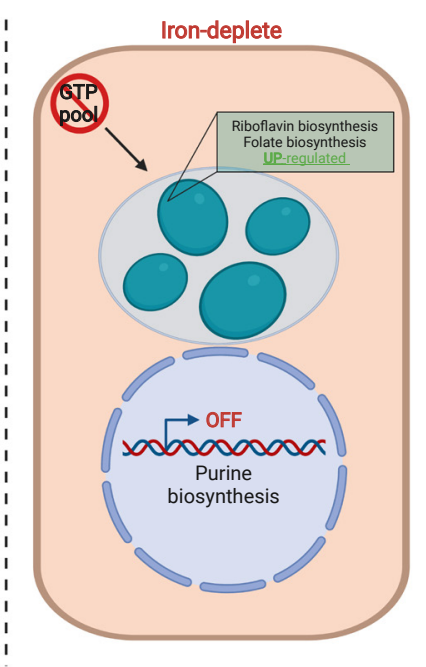

Figure 5. Suppressed host cell purine metabolism is reflected by an up-regulation of GTP-dependent biosynthetic pathways in Chlamydia trachomatis. (A) Dot plot for the ten most activated or suppressed pathways identified by clusterProfiler in BPD24. Dot size reflects the number of genes enriched in the pathway and dot color indicates the statistical significance of pathway enrichment. (B) Simplified depiction of the chlamydial riboflavin biosynthetic pathway with color-coded normalized gene expression data for each gene represented by adjacent circles (BPD24) or diamonds (TRP24). DARPP = 2,5-diamino-6-(5-phospho-D-ribosylamino)-pyrimidin-4(3H)one, ArPP = 5-amino-6-(5-phospho-D-ribosylamino)uracil, ArP = 5-amino-6-(5-phospho-D-ribitylamino)uracil, Ru5P = ribulose-5phosphate, DHPB = 3,4-dihydroxy-2-butanone 4-phosphate, DRL = 6,7-dimethyl-8-ribityllumazine, FAD = flavin adenine dinucleotide. (C) Same as in (B) for the chlamydial tetrahydrofolate biosynthetic pathway. DARPP = 2,5-diamino-6-(5-phospho-D-ribosylamino)-pyrimidin4(3H)-one, $\mathrm{H}_{2} \mathrm{NMP}=7$,8-dihydroneopterin 3-phosphate, $\mathrm{H}_{2} \mathrm{~N}=7$,8-dihydroneopterin, $\mathrm{HMH}_{2} \mathrm{~N}=6$-hydroxymethyl-7,8-dihydropterin, $\mathrm{H}_{2} \mathrm{Pt}$ $=7,8$-dihydro-pteroate, $\mathrm{DHF}=7,8$-dihydrofolate, $\mathrm{THF}=5,6,7,8$-tetrahydrofolate. (D) Proposed model of reciprocal up-regulation of chlamydial riboflavin and THF biosynthesis in the presence of the iron-dependent suppression of purine metabolism. Created with BioRender.com.

\section{Pharmacological inhibition of host cell GTP biosynthesis by mizoribine induces chlamydial persistence.}

Validation of our model that Ctr could sense and respond to GTP deprivation required an independent means of specifically depleting the host GTP pool. We therefore turned to mizoribine (MIZ), a selective inhibitor of inosine monophosphate dehydrogenase (IMPDH1/2) and guanosine monophosphate synthase (GMPS) (Turka et al., 1991; Yokota, 2002). MIZ is a potent inhibitor of mammalian GTP biosynthesis (Hoxhaj et al., 2017) and therefore provided a suitable tool to evaluate whether GTP starvation alone influenced chlamydial development and gene regulation. We treated Ctr-infected HeLa cells with a twofold dilution series of MIZ for $24 \mathrm{~h}$ starting at the time of infection. Chlamydial morphology and genome replication were acutely sensitive to MIZ, with a perceptible reduction in inclusion size (Figure 6A) and significant decrease in genome copy number (Figure 6B) detectable at the lowest concentration of MIZ tested, $12.5 \mu \mathrm{M}$. However, we sought to determine whether MIZ treatment could induce a persistent state in Ctr. We observed that by $100 \mu \mathrm{M} \mathrm{MIZ}$ treatment, abnormal chlamydiae could be detected by confocal immunofluorescent microscopy (Figure 6A) and furthermore that genome equivalents at this concentration were not statistically distinguishable from either the 50 or $200 \mu \mathrm{M}$ treatments (Figure 6B), suggesting that genome replication had been stalled. Therefore, we moved forward with the $100 \mu \mathrm{M}$ MIZ treatment (hereafter MIZ24) and determined if Ctr retained viability when a reactivation (i.e.

Figure 4 cont. (C) Dot plots for the 15 most enriched pathways identified by clusterProfiler in UTD24, BPD24 and TRP24. Dot size reflects the number of genes enriched in the pathway and dot color indicates the statistical significance of pathway enrichment. (D) Enrichment network map for the 15 most enriched pathways identified by clusterProfiler in UTD24, BPD24 and TRP24. Dot size and color are the same as in $(\mathbf{C})$. 
A
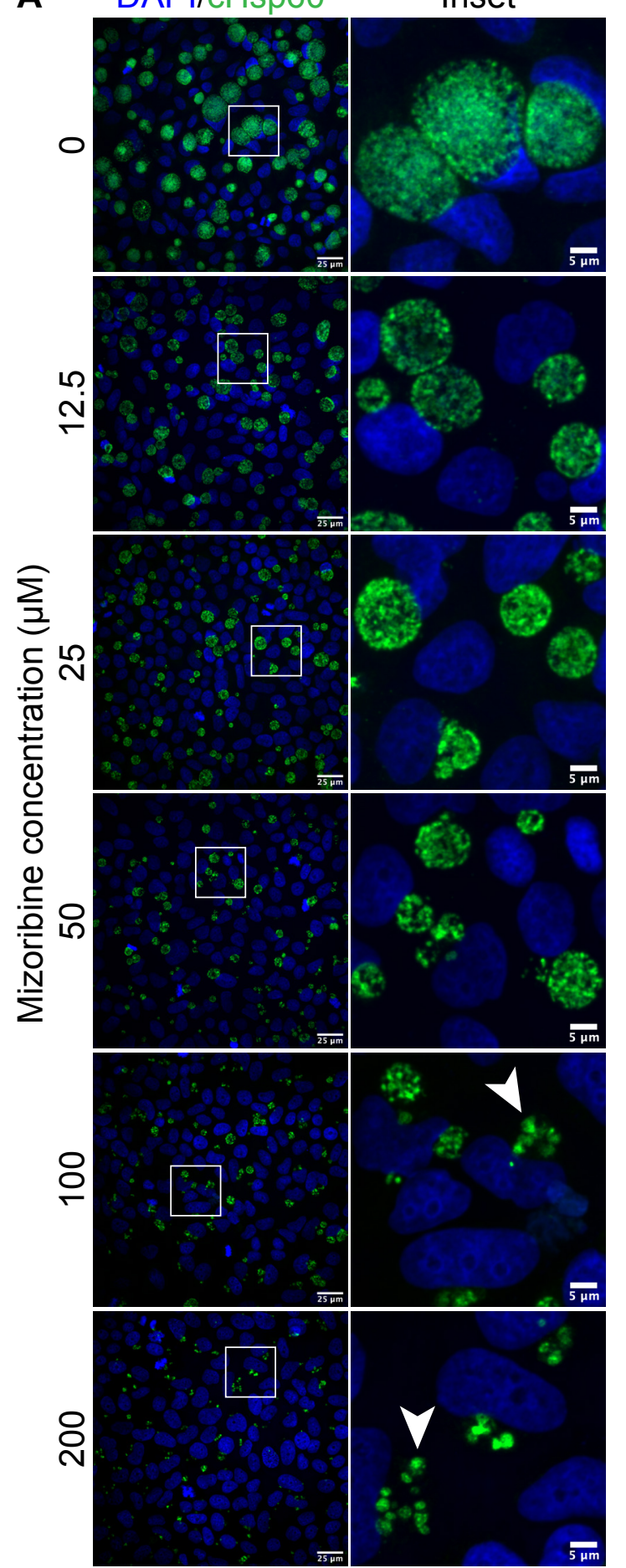

B

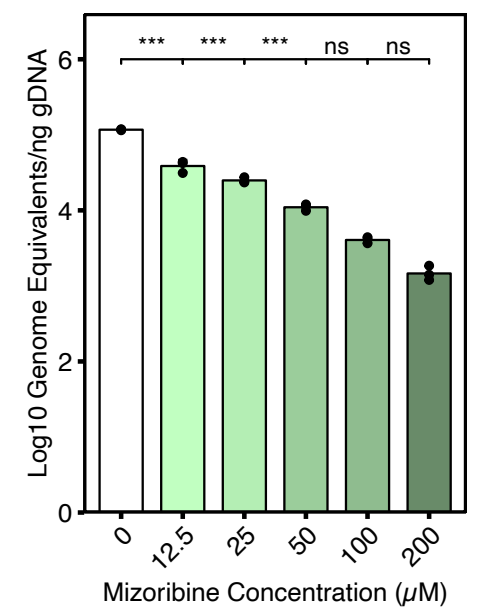

C

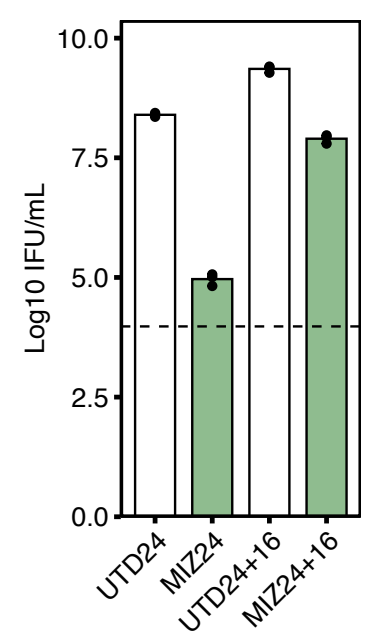

D

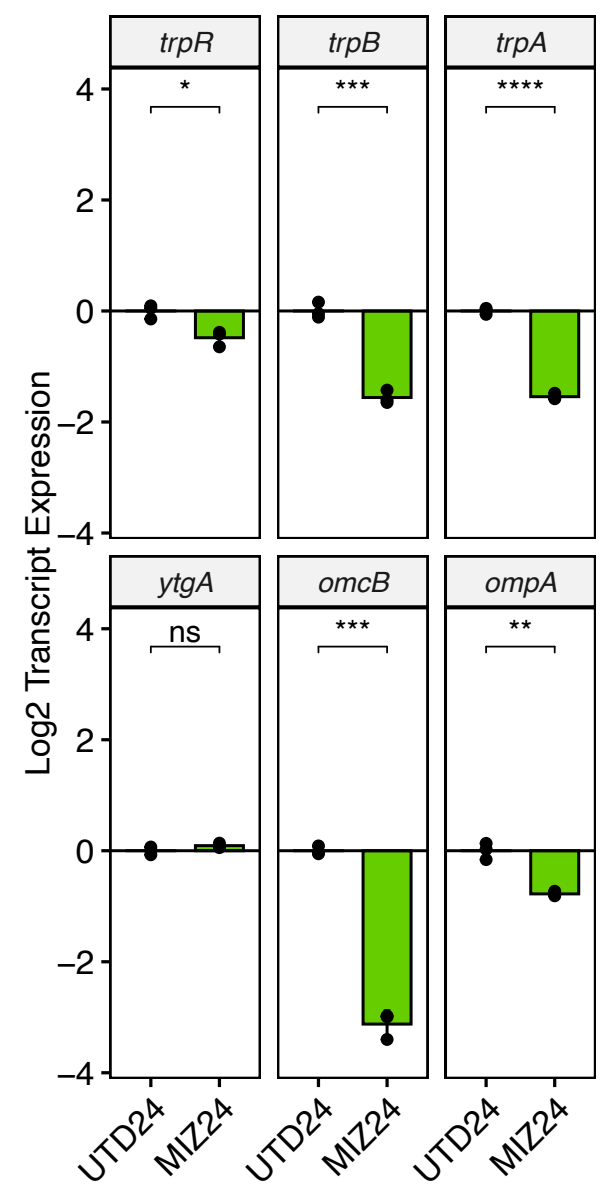

Figure 6. Mizoribine treatment induces chlamydial persistence. (A) Immunofluorescent confocal microscopic analysis of chlamydial morphology following a two-fold dilution series of mizoribine (MIZ) beginning at the time of infection. Micrographs are representative of at least three independent biological replicates $(\mathrm{N}=3)$. Chlamydial organisms were detected by immunostaining against the cytosolic Hsp60 homologs, GroEL_1-GroEL_3. Nuclei were detected by staining with DAPI. Arrowheads indicate aberrantly enlarged bacteria. (B) Determination of genome equivalents under the same MIZ dilution series in (A) by quantitative PCR against the euo locus. (C) Measurement of infectious progeny generation during $100 \mu \mathrm{M}$ MIZ (MIZ24) in a reinfection assay. Reactivation was allowed to proceed for $16 \mathrm{~h}$ by replacement of MIZ-containing media with fresh media. Dotted line indicates calculated limit of detection for the assay. (D) Gene expression profiles for various nutritionally- or developmentally-regulated chlamydial genes during MIZ24 treatment. Statistical significance in all panels was determined by pairwise two-sided unpaired Welch's $t$-test for unequal variance. ${ }^{*}=p<0.05,{ }^{* *}=p<0.01$, $* * *=p<0.001$. All plots represent the mean and standard deviation of three independent biological replicates $(\mathrm{N}=3)$.

withdrawal of the inhibitor) period of $16 \mathrm{~h}$ was introduced (Figure 6C). Recoverable IFUs were reduced roughly 2700fold in MIZ24 relative to UTD24 but recovered to a level only 3-fold lower than UTD24 after reactivation. Thus, Ctr adopts an aberrant morphology and stalls genome replication in the 
bioRxiv preprint doi: https://doi.org/10.1101/2021.08.14.456350; this version posted August 15, 2021. The copyright holder for this preprint (which was not certified by peer review) is the author/funder, who has granted bioRxiv a license to display the preprint in perpetuity. It is made available under aCC-BY 4.0 International license.

presence of MIZ but retains viability, which are physiological hallmarks of chlamydial persistence.

Our transcriptomic analyses indicated that an analysis of gene expression could inform a more robust categorization of the persistent state induced by MIZ. We returned to the panel of genes analyzed in Figure 1E to compare the gene expression profile of MIZ24 to other well characterized persistence models. Unlike BPD and TRP, $M I Z$ down-regulated the expression of the $\operatorname{trpRBA}$ operon, but reproduced the transcriptional profile of $y \operatorname{tg} A$, omcB and ompA found under established persistence models (Figure $1 \mathrm{E}$, Figure $6 \mathrm{D}$ ). It is not surprising that $\operatorname{trpRBA}$ gene expression profiles were not replicated under this condition because the nutritional co-repressors (i.e. iron and tryptophan) were not expected to be negatively affected by MIZ. We additionally analyzed expression of the curated panel of accessory genes (Figure 3 - Figure Supplement 1) in the MIZ24 condition and found that while atpB was significantly down-regulated, amiA, dapL and tyrP were all significantly up-regulated (Figure 6 - Figure Supplement 1). The up-regulation of amiA and dapL implies that the persistent state induced by MIZ24, to a limited extent, may be more comparable to that of BPD24 than TRP24, potentially explaining the comparable bacterial morphology observed between MIZ24 and BPD24 (Figure 1B, Figure $6 A)$.
The depletion of host cell GTP pools in models of persistence elicits specific gene expression profiles in the chlamydial riboflavin and THF biosynthetic pathways.

With the validation of MIZ as a tool for starving Ctr of GTP, we next assayed intracellular GTP levels in mock-infected or Ctr-infected HeLa cells during nutritional stress. To measure the host GTP pool, we adapted a commercially available kit for assaying GTPase activity (Figure 7A, see Materials and Methods). By comparing mock-infected samples, we observed that all nutrient-depleted conditions resulted in a reduction of GTP levels comparable to that observed with MIZ24 (Figure 7B). Interestingly, we observed that infection alone decreased intracellular GTP levels, which may reflect increased competition for this nucleotide between host and pathogen. However, infection could not further reduce the level of GTP from any nutrient-starved condition, suggesting that GTP was inaccessible to Ctr. Whether this is solely the effect of suppressed purine metabolism or if GTP sequestration or depletion occurs is unknown. Therefore, the host cell responds to nutrient limitation by depleting GTP pools, which negatively impacts Ctr as they compete for this critical nutrient to sustain replication and development. We note however that only BPD24 was able to reduce total luminescent output from this assay, which reflects the gross suppression of purine
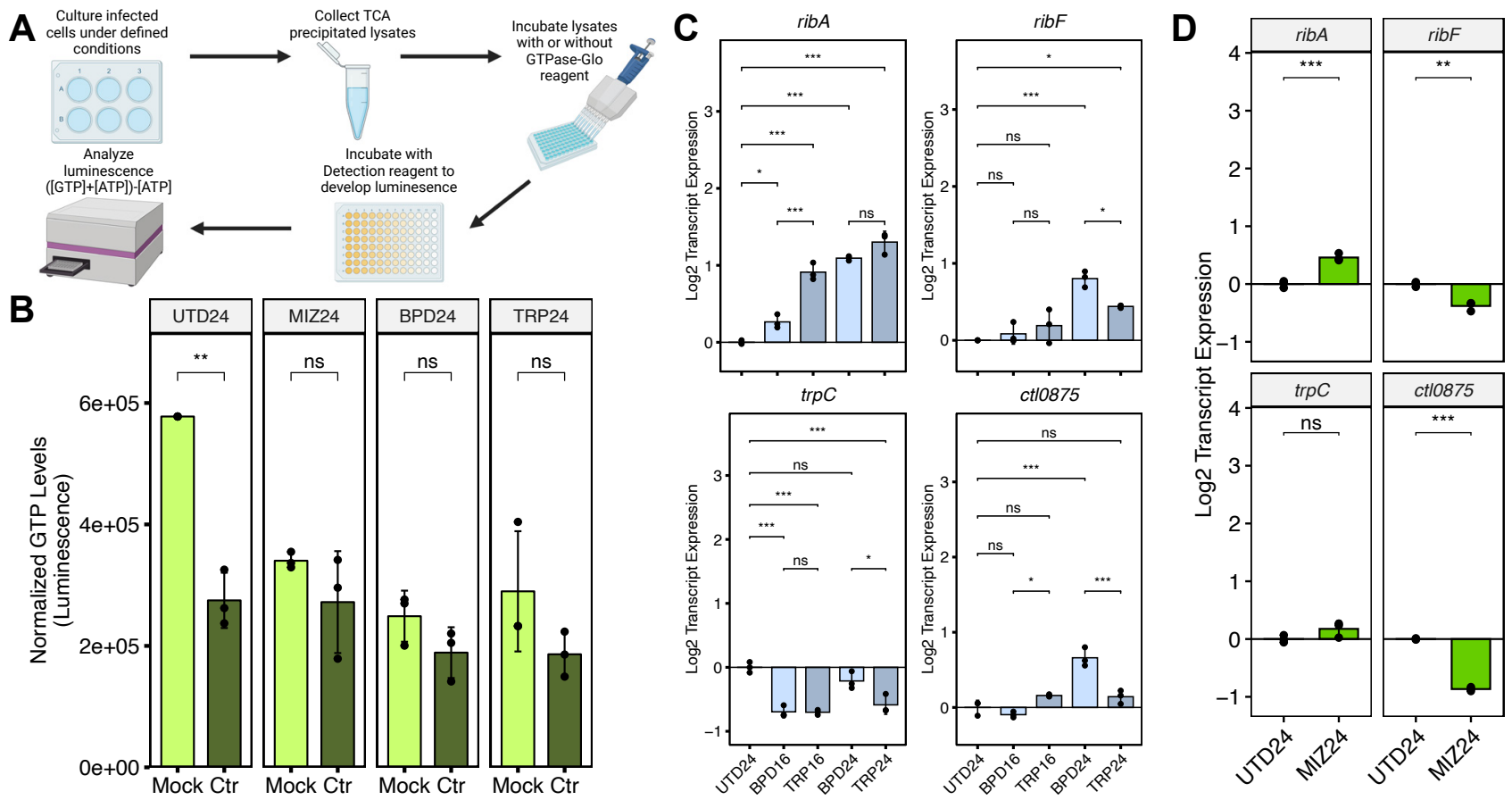

Figure 7. Nutritional stress depletes intracellular GTP levels and corresponds to distinct gene expression profiles in the chlamydial riboflavin and THF biosynthetic pathways. (A) Diagram depicting the experimental workflow for the modified GTPaseGlo assay kit to measure intracellular GTP levels. Created with BioRender.com. (B) Determination of intracellular GTP levels across persistence-inducing conditions using the modified GTPase-Glo assay. All values for each replicate were normalized to the mean of the untreated, mock-infected control group. Statistical significance in all panels was determined by pairwise two-sided unpaired Welch's $t$-test for unequal variance. ${ }^{*}=p<0.05,{ }^{* *}=p<0.01,{ }^{* * *}=p<0.001$, ns $=$ not significant. (C) Gene expression profiles of selected differentially regulated genes in the riboflavin and THF biosynthetic pathways under original persistence models. Statistical significance in all panels was determined by one-way ANOVA followed by Tukey's post-hoc test of honestly significant differences (two-tailed). ${ }^{*}=$ $p<0.05,{ }^{* *}=p<0.01,{ }^{* * *}=p<0.001$, ns $=$ not significant. (D) Same as in (C) for MIZ24. Statistical significance in all panels was determined by pairwise two-sided unpaired Welch's $t$-test for unequal variance. ${ }^{*}=p<0.05,{ }^{* *}=p<0.01,{ }^{* * *}=p<0.001$. All plots represent the mean and standard deviation of three independent biological replicates $(\mathrm{N}=3)$. 
metabolism identified by pathway-level analysis (Figure 7 Figure Supplement 1, Figure 5A).

Finally, we assayed the expression of a subset of genes from the chlamydial riboflavin and THF biosynthetic pathways under our various nutrient-depleted conditions (Figure 7C), focusing on genes we identified as differentially expressed between BPD24 and TRP24 by RNA-seq (e.g. ribF, trpC and ctl0875, Figure 5, B and $\mathrm{C}$ ), with ribA as the non-differentially regulated control. Indeed, relative to UTD24, the expression of ribA was significantly upregulated in BPD24 and TRP24, but not statistically distinguishable between these groups. However, ribF, trpC and $c t / 0875$ all exhibited significantly higher expression in BPD24 compared to TRP24, suggesting that these pathways may respond to other signals specific to iron starvation. In comparison, we find that MIZ24 significantly increased expression of ribA and did not alter trpC expression (Figure 7D), consistent with the BPD24 condition. However, unlike BPD24, both ribF and ct/0875 were significantly down-regulated by MIZ24, indicating a greater influence of iron starvation than GTP starvation on the expression of these pathways. This finding also implied that GTP starvation, while sufficient in the context of mizoribine treatment, is not the major mechanism by which iron starvation induces persistence. Rather, GTP depletion is one of many contributors to persistence. A broader implication is that the transcriptional signature of a secondary stress within the chlamydial transcriptome is not always readily apparent. Their identification requires coanalysis of the host cell transcriptome and functional validation of candidate secondary stress pathways.

\section{DISUCSSION}

Historically, models of nutritional stress during infection have operated under the assumption that downstream phenotypic consequences to the pathogen can be directly attributed to the depletion of the nutrient in question. We challenge this assumption by demonstrating that the nutrient-deprived host cell can deploy an unrelated antibacterial nutritional stress by suppressing GTP biosynthesis, essentially amplifying and diversifying the stress acting upon the pathogen. How this is accomplished is presently unclear. One could argue that chelation of iron by BPD disrupts the iron-sulfur cluster-containing amidophosphoribosyltransferase, PPAT (Itakura and Holmes, 1979). However, this biochemical explanation does not account for the broader transcriptional down-regulation of purine metabolism during BPD24 treatment or the reduction of GTP levels in the TRP24 condition. Thus, a more fundamental process seems to be at play - one that may ultimately benefit the host during persistent infection. In agreement with this is the observation that distantly related eukaryotes, such as the budding yeast Saccharomyces cerevisiae, also suppress purine biosynthesis in the absence of iron, despite lacking iron-dependent enzymes in these pathways (Philpott and Protchenko, 2008; ShakouryElizeh et al., 2003). Future studies of nutritional stress during intracellular bacterial infection may require a more careful examination of the effect on host cells and the ways in which these effects condition pathogen responses and survival.
The pro-inflammatory cytokine IFNg has been attributed a major role in the host anti-chlamydial immune response (Finethy and Coers, 2016). Much of this antichlamydial activity has been explained by the IFNgmediated induction of IDO1, which catabolizes host cell tryptophan pools to starve Ctr of this essential amino acid (Beatty et al., 1994; Taylor and Feng, 1991). Whether IDO1 overexpression is sufficient to inhibit chlamydial growth has not been investigated. Instead, IDO1 relevance is based on tryptophan supplementation studies and subsequent rescue of normal growth (Beatty et al., 1994; Byrne et al., 1986). Similarly, studies with IDO1 inhibitors, such as levo-1methyl-tryptophan (L-1MT) only led to a partial rescue of growth (Ibana et al., 2011). Both published results remain consistent with additional stresses distinct from tryptophan catabolism by IDO1 being involved in IFNg-mediated growth inhibition. IFNg has also been shown to suppress purine metabolism by inhibiting elF4E expression to reduce translation of genes in the purine biosynthetic pathway in primary human macrophages (an effect that depends on IFNg-mediated IDO1 induction) (Ivashkiv, 2018; Su et al., 2015). This would be analogous to GTP depletion being an outcome of tryptophan starvation. Thus, it may be that reducing purine nucleotide levels, and specifically the GTP pool, is an evolved and redundant immune response of the host cell.

Herein, we provide evidence that both primary and secondary effects of a stress contribute to chlamydial persistence. The character of the chlamydial transcriptome also supports the notion that a stressed host cell induces subsequent stresses. Growth of infected cells in iron- or tryptophan-depleted media yielded transcriptomic profiles consisting of a "core" and an "accessory" component. The latter is specific to the original stress, and could represent remnants of initial chlamydial response, only deteriorating as adverse effects accumulate. On the other hand, the core component could be associated with metabolic consequences that are common to iron and tryptophan starvation, of which reduction in GTP levels is an example. We emphasize that prominent differences remain in the transcriptome components, and a more careful and detailed study is needed to establish their relevance to chlamydial persistence. Based on our collective data, a picture emerges of persistence as a deceptively similar process underpinned by a response that has stress-dependent and -independent components. This response is shaped by the different actions of the primary stress on the pathogen and the host cell, the latter involving the induction of subsequent waves of metabolically oriented stressors that target the pathogen. In other words, despite using a single-stressor experimental model, subsequent stresses with antimicrobial functions are induced, forcing Chlamydia to adapt to not just one, but two or more simultaneous stresses. With a limited repertoire of stress adaptation strategies, Chlamydiae are likely more sensitive to these simultaneous stressors than other intracellular bacterial pathogens; this does not discount the potential relevance of such combined effects in these experimental systems but instead argues for their careful examination in future studies. 
bioRxiv preprint doi: https://doi.org/10.1101/2021.08.14.456350; this version posted August 15, 2021. The copyright holder for this preprint (which was not certified by peer review) is the author/funder, who has granted bioRxiv a license to display the preprint in perpetuity. It is made available under aCC-BY 4.0 International license.

\section{ACKNOWLEDGMENTS}

We would like to acknowledge the members of the Carabeo laboratory for their critical feedback on the development of this project. We would also like to acknowledge the input of Dr. John Mishler-Elmore, Technical Services Scientist I at Promega Corporation for their invaluable feedback on the establishment of the GTPase-Glo assay kit to measure intracellular GTP levels. This work was supported by NIAID grant R01-AI132406 to RAC. The University of Nebraska DNA Sequencing Core receives partial support from the National Institute for General Medical Science (NIGMS) INBRE - P20GM103427-19 grant as well as The Fred \& Pamela Buffett Cancer Center Support Grant - P30 CA036727. This publication's contents are the sole responsibility of the authors and do not necessarily represent the official views of the NIH or NIGMS.

\section{AUTHOR CONTRIBUTIONS}

NDP and RAC designed and analyzed the experiments. NDP performed the experiments. NDP and RAC wrote and edited the manuscript.

\section{DECLARATION OF INTERESTS}

The authors declare no conflicts of interest.

\section{REFERENCES}

AbdelRahman, Y.M., Belland, R.J., 2005. The chlamydial developmental cycle. FEMS Microbiol. Rev. 29, 949-959. https://doi.org/10.1016/j.femsre.2005.03.002

Abreu, R., Essler, L., Giri, P., Quinn, F., 2020. Interferon-gamma promotes iron export in human macrophages to limit intracellular bacterial replication. PLoS One 15, e0240949.

Adams, N.E., Thiaville, J.J., Proestos, J., Juárez-Vázquez, A.L., McCoy, A.J., Barona-Gómez, F., Iwata-Reuyl, D., de CrécyLagard, V., Maurelli, A.T., 2014. Promiscuous and adaptable enzymes fill "Holes" in the tetrahydrofolate pathway in Chlamydia species. MBio 5, 1-14. https://doi.org/10.1128/mBio.01378-14

Al-Younes, H.M., Rudel, T., Brinkmann, V., Szczepek, A.J., Meyer, T.F., 2001. Low iron availability modulates the course of Chlamydia pneumoniae infection. Cell. Microbiol. 3, 427-437.

Anders, S., Pyl, P.T., Huber, W., 2015. HTSeq-a Python framework to work with high-throughput sequencing data. Bioinformatics 31, 166-169. https://doi.org/10.1093/bioinformatics/btu638

Ardissone, S., Scherler, A., Pillonel, T., Martin, V., KebbiBeghdadi, C., Greub, G., 2020. Transcriptional Landscape of Waddlia chondrophila Aberrant Bodies Induced by Iron Starvation. Microorg. https://doi.org/10.3390/microorganisms8121848

Barry III, C.E., Brickman, T.J., Hackstadt, T., 1993. Hc1-mediated effects on DNA structure: a potential regulator of chlamydial development. Mol. Microbiol. 9, 273-283. https://doi.org/10.1111/j.1365-2958.1993.tb01689.x

Beatty, W.L., Belanger, T.A., Desai, A.A., Morrison, R.P., Byrne, G.I., 1994. Tryptophan depletion as a mechanism of gamma interferon-mediated chlamydial persistence. Infect. Immun. 62, 3705-3711.

Beatty, W.L., Byrne, G.I., Morrison, R.P., 1993. Morphologic and antigenic characterization of interferon gamma- mediated persistent Chiamydia trachomatis infection in vitro. Proc. Natl. Acad. Sci. U. S. A. 90, 3998-4002. https://doi.org/10.1073/pnas.90.9.3998

Beatty, W.L., Morrison, R.P., Byrne, G.I., 1995. Reactivation of persistent Chlamydia trachomatis infection in cell culture. Infect. Immun. 63, 199-205. https://doi.org/10.1128/iai.63.1.199-205.1995

Becker, E., Hegemann, J.H., 2014. All subtypes of the Pmp adhesin family are implicated in chlamydial virulence and show species-specific function. Microbiologyopen 3, 544556. https://doi.org/https://doi.org/10.1002/mbo3.186

Belland, R.J., Nelson, D.E., Virok, D., Crane, D.D., Hogan, D., Sturdevant, D., Beatty, W.L., Caldwell, H.D., 2003. Transcriptome analysis of chlamydial growth during IFNgamma-mediated persistence and reactivation. Proc. Natl. Acad. Sci. U. S. A. 100, 15971-15976.

https://doi.org/10.1073/pnas.2535394100

Blighe, K., Rana, S., Lewis, M., 2021. EnhancedVolcano: Publication-ready volcano plots with enhanced colouring and labeling. https://doi.org/10.18129/B9.bioc.EnhancedVolcano

Brinkworth, A.J., Wildung, M.R., Carabeo, R.A., 2018. Genomewide Transcriptional Responses of Iron-Starved Chlamydia trachomatis Reveal Prioritization of Metabolic Precursor Synthesis over Protein Translation. mSystems 3, e00184-17.

Brockett, M.R., Liechti, G.W., 2021. Persistence alters the interaction between Chlamydia trachomatis and its host cell. Infect. Immun. 0, IAI.00685-20. https://doi.org/10.1128/IAI.00685-20

Byrne, G.I., Lehmann, L.K., Landry, G.J., 1986. Induction of tryptophan catabolism is the mechanism for gammainterferon-mediated inhibition of intracellular Chlamydia psittaci replication in T24 cells. Infect. Immun. 53, 347-351.

Caldwell, H.D., Kromhout, J., Schachter, J., 1981. Purification and partial characterization of the major outer membrane protein of Chlamydia trachomatis. Infect. Immun. 31, 11611176.

Carrasco, J.A., Tan, C., Rank, R.G., Hsia, R., Bavoil, P.M., 2011. Altered developmental expression of polymorphic membrane proteins in penicillin-stressed Chlamydia trachomatis. Cell. Microbiol. 13, 1014-1025. https://doi.org/https://doi.org/10.1111/j.14625822.2011.01598.x

Eickhoff, M., Thalmann, J., Hess, S., Martin, M., Laue, T., Kruppa, J., Brandes, G., Klos, A., 2007. Host Cell Responses to Chlamydia pneumoniae in Gamma Interferon-Induced Persistence Overlap Those of Productive Infection and Are Linked to Genes Involved in Apoptosis, Cell Cycle, and Metabolism. Infect. Immun. 75, 2853-2863.

https://doi.org/10.1128/IAI.01045-06

Eisenreich, W., Rudel, T., Heesemann, J., Goebel, W., 2021. Persistence of Intracellular Bacterial Pathogens-With a Focus on the Metabolic Perspective . Front. Cell. Infect. Microbiol.

Engström, P., Bailey, L., Önskog, T., Bergström, S., Johansson, J., 2010. A comparative study of RNA and DNA as internal gene expression controls early in the developmental cycle of Chlamydia pneumoniae. FEMS Immunol. Med. Microbiol. 58, 244-253. https://doi.org/10.1111/j.1574695X.2009.00631.x

Finethy, R., Coers, J., 2016. Sensing the enemy, containing the threat: cell-autonomous immunity to Chlamydia trachomatis. FEMS Microbiol. Rev. 40, 875-893. https://doi.org/10.1093/femsre/fuw027

Finlay, B.B., McFadden, G., 2006. Anti-Immunology: Evasion of the Host Immune System by Bacterial and Viral Pathogens. Cell 124, 767-782. https://doi.org/https://doi.org/10.1016/j.cell.2006.01.034

Hackstadt, T., Baehr, W., Ying, Y., 1991. Chlamydia trachomatis developmentally regulated protein is homologous to eukaryotic histone H1. Proc. Natl. Acad. Sci. U. S. A. 88, 
bioRxiv preprint doi: https://doi.org/10.1101/2021.08.14.456350; this version posted August 15, 2021. The copyright holder for this preprint (which was not certified by peer review) is the author/funder, who has granted bioRxiv a license to display the preprint in perpetuity. It is made available under aCC-BY 4.0 International license.

3937-3941. https://doi.org/10.1073/pnas.88.9.3937

Hatch, N.D., Ouellette, S.P., 2020. Inhibition of tRNA Synthetases Induces Persistence in Chlamydia. Infect. Immun. 1-15. https://doi.org/10.1128/iai.00943-19

Hayward, R.J., Humphrys, M.S., Huston, W.M., Myers, G.S.A., 2021. Dual RNA-seq analysis of in vitro infection multiplicity and RNA depletion methods in Chlamydia-infected epithelial cells. Sci. Rep. 11, 10399. https://doi.org/10.1038/s41598-021-89921-x

Hoxhaj, G., Hughes-Hallett, J., Timson, R.C., Ilagan, E., Yuan, M., Asara, J.M., Ben-Sahra, I., Manning, B.D., 2017. The mTORC1 Signaling Network Senses Changes in Cellular Purine Nucleotide Levels. Cell Rep. 21, 1331-1346. https://doi.org/https://doi.org/10.1016/j.celrep.2017.10.029

Ibana, J.A., Belland, R.J., Zea, A.H., Schust, D.J., Nagamatsu, T., AbdelRahman, Y.M., Tate, D.J., Beatty, W.L., Aiyar, A.A., Quayle, A.J., 2011. Inhibition of indoleamine 2,3dioxygenase activity by levo-1-methyl tryptophan blocks gamma interferon-induced chlamydia trachomatis persistence in human epithelial cells. Infect. Immun. 79, 4425-4437. https://doi.org/10.1128/IAI.05659-11

Itakura, M., Holmes, E.W., 1979. Human amidophosphoribosyltransferase. An oxygen-sensitive ironsulfur protein. J. Biol. Chem. 254, 333-338. https://doi.org/10.1016/s0021-9258(17)37922-x

Ivashkiv, L.B., 2018. IFNy: signalling, epigenetics and roles in immunity, metabolism, disease and cancer immunotherapy. Nat. Rev. Immunol. 18, 545-558. https://doi.org/10.1038/s41577-018-0029-z

Kim, D., Langmead, B., Salzberg, S.L., 2015. HISAT: a fast spliced aligner with low memory requirements. Nat. Methods 12, 357-360. https://doi.org/10.1038/nmeth.3317

Love, M.I., Huber, W., Anders, S., 2014. Moderated estimation of fold change and dispersion for RNA-seq data with DESeq2. Genome Biol. 15, 550. https://doi.org/10.1186/s13059-0140550-8

Luo, W., Brouwer, C., 2013. Pathview: an R/Bioconductor package for pathway-based data integration and visualization. Bioinformatics 29, 1830-1831. https://doi.org/10.1093/bioinformatics/btt285

Matsumoto, A., Manire, G.P., 1970. Electron microscopic observations on the effects of penicillin on the morphology of Chlamydia psittaci. J. Bacteriol. 101, 278-285. https://doi.org/10.1128/jb.101.1.278-285.1970

McClarty, G., Fan, H., 1993. Purine metabolism by intracellular Chlamydia psittaci. J. Bacteriol. 175, 4662-4669. https://doi.org/10.1128/jb.175.15.4662-4669.1993

Nairz, M., Haschka, D., Demetz, E., Weiss, G., 2014. Iron at the interface of immunity and infection. Front. Pharmacol. 5. https://doi.org/10.3389/fphar.2014.00152

Ouellette, S.P., Hatch, T.P., AbdelRahman, Y.M., Rose, L.A., Belland, R.J., Byrne, G.I., 2006. Global transcriptional upregulation in the absence of increased translation in Chlamydia during IFNy-mediated host cell tryptophan starvation. Mol. Microbiol. 62, 1387-1401. https://doi.org/10.1111/j.1365-2958.2006.05465.x

Ouellette, S.P., Rueden, K.J., Rucks, E.A., 2016. Tryptophan codon-dependent transcription in chlamydia pneumoniae during gamma interferon-mediated tryptophan limitation. Infect. Immun. 84, 2703-2713. https://doi.org/10.1128/IAI.00377-16

Panzetta, M.E., Valdivia, R.H., Saka, H.A., 2018. Chlamydia Persistence: A Survival Strategy to Evade Antimicrobial Effects in-vitro and in-vivo. Front. Microbiol. 9, 1-11. https://doi.org/10.3389/fmicb.2018.03101

Phillips-Campbell, R., Kintner, J., Schoborg, R. V., 2014. Induction of the Chlamydia muridarum Stress/Persistence Response Increases Azithromycin Treatment Failure in a
Murine Model of Infection. Antimicrob. Agents Chemother. 58, 1782-1784. https://doi.org/10.1128/AAC.02097-13

Philpott, C.C., Protchenko, O., 2008. Response to Iron Deprivation in Saccharomyces cerevisiae. Eukaryot. Cell 7, 20-27. https://doi.org/10.1128/EC.00354-07

Pokorzynski, N.D., Brinkworth, A.J., Carabeo, R., 2019. A bipartite iron-dependent transcriptional regulation of the tryptophan salvage pathway in Chlamydia trachomatis. Elife $8,1-32$.

Pokorzynski, N.D., Hatch, N.D., Ouellette, S.P., Carabeo, R.A., 2020. The iron-dependent repressor YtgR is a tryptophandependent attenuator of the trpRBA operon in Chlamydia trachomatis. Nat. Commun. 11, 6430. https://doi.org/10.1038/s41467-020-20181-5

Prentice, A.M., Ghattas, H., Cox, S.E., 2007. Host-Pathogen Interactions: Can Micronutrients Tip the Balance? J. Nutr. 137, 1334-1337. https://doi.org/10.1093/jn/137.5.1334

Raulston, J.E., 1997. Response of Chlamydia trachomatis serovar $E$ to iron restriction in vitro and evidence for ironregulated chlamydial proteins. Infect. Immun. 65, 45394547.

Schindelin, J., Arganda-Carreras, I., Frise, E., Kaynig, V., Longair, M., Pietzsch, T., Preibisch, S., Rueden, C., Saalfeld, S., Schmid, B., Tinevez, J.Y., White, D.J., Hartenstein, V., Eliceiri, K., Tomancak, P., Cardona, A., 2012. Fiji: An opensource platform for biological-image analysis. Nat. Methods 9, 676-682. https://doi.org/10.1038/nmeth.2019

Shakoury-Elizeh, M., Tiedeman, J., Rashford, J., Ferea, T., Demeter, J., Garcia, E., Rolfes, R., Brown, P.O., Botstein, D., Philpott, C.C., 2003. Transcriptional Remodeling in Response to Iron Deprivation in Saccharomyces cerevisiae. Mol. Biol. Cell 15, 1233-1243. https://doi.org/10.1091/mbc.e03-09-0642

Shannon, P., Markiel, A., Ozier, O., Baliga, N.S., Wang, J.T., Ramage, D., Amin, N., Schwikowski, B., Ideker, T., 2003. Cytoscape: A Software Environment for Integrated Models of Biomolecular Interaction Networks. Genome Res. 13, 2498-2504. https://doi.org/10.1101/gr.1239303

Shtrichman, R., Samuel, C.E., 2001. The role of gamma interferon in antimicrobial immunity. Curr. Opin. Microbiol. 4, 251-259. https://doi.org/https://doi.org/10.1016/S13695274(00)00199-5

Skilton, R.J., Cutcliffe, L.T., Barlow, D., Wang, Y., Salim, O., Lambden, P.R., Clarke, I.N., 2009. Penicillin Induced Persistence in Chlamydia trachomatis: High Quality Time Lapse Video Analysis of the Developmental Cycle. PLoS One 4, e7723.

Su, X., Yu, Y., Zhong, Y., Giannopoulou, E.G., Hu, X., Liu, H., Cross, J.R., Rätsch, G., Rice, C.M., Ivashkiv, L.B., 2015. Interferon-y regulates cellular metabolism and mRNA translation to potentiate macrophage activation. Nat. Immunol. 16, 838-849. https://doi.org/10.1038/ni.3205

Szklarczyk, D., Gable, A.L., Lyon, D., Junge, A., Wyder, S., Huerta-Cepas, J., Simonovic, M., Doncheva, N.T., Morris, J.H., Bork, P., Jensen, L.J., Mering, C. von, 2019. STRING v11: protein-protein association networks with increased coverage, supporting functional discovery in genome-wide experimental datasets. Nucleic Acids Res. 47, D607-D613. https://doi.org/10.1093/nar/gky1131

Taylor, M.W., Feng, G.S., 1991. Relationship between interferongamma, indoleamine 2,3-dioxygenase, and tryptophan catabolism. Faseb. J. 5, 2516-2522.

Thompson, C.C., Carabeo, R.A., 2011. An optimal method of iron starvation of the obligate intracellular pathogen, Chlamydia trachomatis. Front. Microbiol. 2. https://doi.org/10.3389/fmicb.2011.00020

Thompson, C.C., Nicod, S.S., Malcolm, D.S., Grieshaber, S.S., Carabeo, R.A., 2012. Cleavage of a putative metal 
bioRxiv preprint doi: https://doi.org/10.1101/2021.08.14.456350; this version posted August 15, 2021. The copyright holder for this preprint (which was not certified by peer review) is the author/funder, who has granted bioRxiv a license to display the preprint in perpetuity. It is made available under aCC-BY 4.0 International license.

permease in Chlamydia trachomatis yields an irondependent transcriptional repressor. Proc. Natl. Acad. Sci. U. S. A. 109, 10546-51.

https://doi.org/10.1073/pnas.1201398109

Tipples, G., McClarty, G., 1993. The obligate intracellular bacterium Chlamydia trachomatis is auxotrophic for three of the four ribonucleoside triphosphates. Mol. Microbiol. 8, 1105-1114. https://doi.org/10.1111/j.13652958.1993.tb01655.x

Turka, L.A., Dayton, J., Sinclair, G., Thompson, C.B., Mitchell, B.S., 1991. Guanine ribonucleotide depletion inhibits T cell activation. Mechanism of action of the immunosuppressive drug mizoribine. J. Clin. Invest. 87, 940-948. https://doi.org/10.1172/JCl115101

Vandesompele, J., De Preter, K., Pattyn, F., Poppe, B., Van Roy, N., De Paepe, A., Speleman, F., 2002. Accurate normalization of real-time quantitative RT-PCR data by geometric averaging of multiple internal control genes. Genome Biol. 3, research0034.1. https://doi.org/10.1186/gb-2002-3-7-research0034
Wickham, H., 2009. ggplot2: Elegant Graphics for Data Analysis. Springer-Verlag New York.

Wyrick, P.B., 2010. Chlamydia trachomatis Persistence In Vitro: An Overview. J. Infect. Dis. 201, 88-95. https://doi.org/10.1086/652394

Wyrick, P.B., Knight, S.T., 2004. Pre-exposure of infected human endometrial epithelial cells to penicillin in vitro renders Chlamydia trachomatis refractory to azithromycin. J. Antimicrob. Chemother. 54, 79-85. https://doi.org/10.1093/jac/dkh283

Yokota, S., 2002. Mizoribine: Mode of action and effects in clinical use. Pediatr. Int. 44, 196-198. https://doi.org/https://doi.org/10.1046/j.13288067.2002.01536.X

Yu, G., Wang, L.-G., Han, Y., He, Q.-Y., 2012. clusterProfiler: an $\mathrm{R}$ Package for Comparing Biological Themes Among Gene Clusters. Omi. A J. Integr. Biol. 16, 284-287. https://doi.org/10.1089/omi.2011.0118

\section{MATERIALS AND METHODS}

\section{Data and materials availability}

All sequencing data generated in this study have been deposited at the NCBI Gene Expression Omnibus (GEO; Accession number: GSE179003) and are publicly available as of the date of publication. All other source data and original code for the analysis of RNA-sequencing datasets and other experimental data have been deposited at Mendeley Data (DOI: 10.17632/vxvznn6bck.1) and are publicly available as of the date of publication. Microscopy data reported in this paper will be shared by the corresponding author upon request. Any additional information required to reanalyze the data reported in this paper is available from the corresponding author upon request.

\section{Cell lines}

Human female cervical epithelial adenocarcinoma HeLa cells (RRID: CVCL_1276)

were cultured at $37^{\circ} \mathrm{C}$ with $5 \%$ atmospheric CO2 in Dulbecco's Modified Eagle Medium (DMEM; Gibco, Thermo Fisher Scientific, Waltham, MA, USA) supplemented with $10 \mu \mathrm{g} / \mathrm{mL}$ gentamicin, $2 \mathrm{mM}$ L-glutamine, and $10 \%(\mathrm{v} / \mathrm{v}$ ) filter sterilized fetal bovine serum (FBS). For all experiments, HeLa cells were cultured between passage numbers 3 and 15. HeLa cells were originally authenticated by ATCC via STR profiling and isoenzyme analysis per ATCC specifications.

\section{Bacterial strains}

Chlamydia trachomatis serovar L2 (434/Bu) was originally obtained from Dr. Ted Hackstadt (Rocky Mountain National Laboratory, NIAID). Chlamydial EBs were isolated from infected HeLa cells at 36-40 hr post-infection (hpi) and purified by density gradient centrifugation essentially as described (Caldwell et al., 1981). For infections, at $80-90 \%$ confluency, cells were first washed with Hanks Buffered Saline Solution (HBSS; Gibco, Thermo Fisher Scientific) and ice-cold inoculum prepared in HBSS at the indicated multiplicity of infection was overlaid onto the cell monolayer. To synchronize the infection, inoculated cells were then centrifuged for $15 \mathrm{~min}$ at $500 \times \mathrm{xCF}, 4^{\circ} \mathrm{C}$ in an Eppendorf $5810 \mathrm{R}$ tabletop centrifuge with an A-4-81 rotor. The inoculum was then aspirated and pre-warmed DMEM (or relevant media with treatment supplementation) was added to the cells. Infected cultures were then returned to the tissue culture incubator until the indicated time post-infection.

\section{Treatment conditions}

For iron starvation and media-defined tryptophan starvation, treatment was performed essentially as described previously (Pokorzynski et al., 2020, 2019). In brief, 100 mM 2,2-bipyridyl (Sigma Aldrich, St. Louis, MO, USA; CAS: 366-18-7) prepared in dimethyl sulfoxide (DMSO) was added to complete DMEM (or tryptophan-depleted DMEM-F12, as described below) at a working concentration of $100 \mu \mathrm{M}$ at the start of infection (BPD24) or at 8 hpi (BPD16). When added after the time of infection, cells were first washed with HBSS prior to bipyridyl treatment. Tryptophan depletion was performed by first washing cells with HBSS and then replacing complete DMEM with tryptophan-depleted DMEM-F12 (U.S. Biological Life Sciences, Salem, MA, USA). Media was replaced either at the time of infection (TRP24) or at $8 \mathrm{hpi}$ (TRP16). Treated cells were then returned to the tissue culture incubator for the remainder of the experimental time course. Mizoribine (Sigma Aldrich, CAS: 50924-49-7) was prepared as a $100 \mathrm{mM}$ stock solution in DMSO, stored at $-80^{\circ} \mathrm{C}$, and used at the indicated concentrations starting at the time of infection (MIZ24).

\section{Nucleic acid preparation}

RNA was harvested from C. trachomatis-infected cells by scraping one or two wells of a 6 -well tissue culture plate in a total volume of $500 \mu \mathrm{L}$ Trizol Reagent (Thermo Fisher Scientific). Samples were transferred to RNase-free o-ring capped tubes containing $\sim 100 \mu \mathrm{L}$ volume of zirconia beads and thoroughly vortexed for $10 \mathrm{~min}$ to rupture bacterial cells. Zirconia beads were pelleted by centrifugation at $21,000 \mathrm{xg}$ for $10 \mathrm{~min}$ at $4^{\circ} \mathrm{C}$ and supernatant was transferred to an RNase-free tube containing $100 \mu \mathrm{L}$ chloroform (Sigma Aldrich). Samples were vortexed for $15 \mathrm{~s}$ prior to a 10 min $\mathrm{RT}^{\circ} \mathrm{C}$ incubation. Phases were then separated by centrifugation at $21,000 \times \mathrm{xg}$ for $15 \mathrm{~min}$ at $4^{\circ} \mathrm{C}$. The aqueous top layer was transferred to an RNase-free tube containing $250 \mu \mathrm{L} 100 \%$ ethanol to precipitate RNA. Samples were briefly vortexed and then applied to an RNA collection column provided in the PureLink ${ }^{\mathrm{TM}}$ RNA Mini Kit (Invitrogen, Thermo Fisher Scientific). RNA was isolated as described by the manufacturer with an on-column DNA digestion using the PureLink ${ }^{\text {TM }}$ DNase Set (Invitrogen, Thermo Fisher Scientific). RNA was eluted in nuclease-free $\mathrm{H}_{2} \mathrm{O}$ and stored at $-20^{\circ} \mathrm{C}$ for short-term storage or $-80^{\circ} \mathrm{C}$ for long-term storage.

Complementary DNA (cDNA) was generated using 1-2 $\mu$ g of RNA as a template for the SuperScript IV Reverse Transcriptase (RT) VILO master mix (Invitrogen, Thermo Fisher Scientific) with a no-RT control reaction in a half-reaction volume following manufacturer protocols. The no-RT control sample was screened for DNA contamination by qPCR against the euo locus (see Data S7 for full list of oligonucleotide primers). 
bioRxiv preprint doi: https://doi.org/10.1101/2021.08.14.456350; this version posted August 15, 2021. The copyright holder for this preprint (which was not certified by peer review) is the author/funder, who has granted bioRxiv a license to display the preprint in perpetuity. It is made available under aCC-BY 4.0 International license.

Genomic DNA (gDNA) was harvested from parallel well(s) of a 6-well plate in $200 \mu \mathrm{L}$ ice-cold PBS $+10 \%$ Proteinase K and processed through the DNeasy Blood and Tissue Kit following manufacture protocols (QIAGEN, Hilden, Germany). gDNA was stored at $-20^{\circ} \mathrm{C}$ for short-term storage or $-80^{\circ} \mathrm{C}$ for longterm storage.

For the preparation of RNA-sequencing libraries, $10 \mu \mathrm{g}$ of RNA collected as described above, with an additional round of on-column DNA digestion, was processed in parallel $5 \mu \mathrm{g}$ aliquots through the RiboMinus ${ }^{\mathrm{TM}}$ Transcriptome Isolation Kit (Invitrogen, Thermo Fisher Scientific) essentially as described in the manufacturer protocol with the exception that the magnetic beads were loaded with $3 \mu \mathrm{L}$ of the pan-prokaryotic rRNA probe as well as $4 \mu \mathrm{L}$ of the eukaryotic rRNA probe to deplete both host and chlamydial rRNA simultaneously. The resulting rRNA-depleted samples were concentrated in the RNA Clean and Concentrator ${ }^{\mathrm{TM}}$ Kit (Zymo Research, Irvine, CA, USA) and submitted to the University of Nebraska DNA Sequencing Core for library preparation and RNA-sequencing.

\section{Library preparation and RNA-sequencing}

Submitted RNA samples were determined to be of suitable quality by fragment analysis on an Agilent 2100 Bioanalyzer (Agilent, Santa Clara, CA, USA). TruSeq Stranded Total RNA library preparation kit (Illumina, San Diego, CA, USA) was used to generate RNA-sequencing libraries following manufacturer protocols with a starting amount of $100 \mathrm{ng}$ rRNA-depleted RNA. Depletion of rRNA in the TruSeq kit was performed by the addition of $2.5 \mu \mathrm{L}$ each of standard rRNA Removal Mix (RRM) or Prokaryotic RRM. Quality of prepared libraries was determined by concentration and fragment analysis as above. Libraries were sequenced on an Illumina NextSeq NS550 (75 bp single read high output flow cell) or NovaSeq 6000 (75 bp single read SP-100 flow cell) Across replicates, the proportion of sequenced bases with a quality score higher than 30 was at least $95 \%$.

\section{Host-pathogen RNA-sequencing analysis}

Transcriptomes were processed using the Galaxy server, version 21.05.1 (usegalaxy.org). Individual sequencing files for each condition within a replicate were concatenated and processed using the fastp application to filter low quality reads, trim reads and cut adapter sequences. Sequences were then aligned to either the Chlamydia trachomatis 434/Bu (ASM6858v1) genome assembly or the Homo sapiens GRCh38 genome assembly using HISAT2 (Kim et al., 2015). Read counts were generated using htseq-count (Anders et al., 2015) and output files were exported and compiled for differential gene expression analysis by DESeq2 in R (Love et al., 2014). Principal component analysis was performed on the regularized log-transformed count data. Volcano plots were generated using the EnhancedVolcano R package (Blighe et al., 2021). Gene set enrichment analysis for KEGG pathways was conducted using the clusterProfiler R package (Yu et al., 2012). Mapping of gene expression data to KEGG pathways was performed using the Pathview package in R (Luo and Brouwer, 2013). Gene network maps were generated by submitting gene lists to the STRING database (Szklarczyk et al., 2019) and then formatting networks in Cytoscape (Shannon et al., 2003). Note that any chlamydial genes not recognized by STRING were automatically filtered out during analysis.

\section{Quantitative PCR}

All quantitative PCR (qPCR) assays were performed using Power Up ${ }^{\mathrm{TM}}$ SYBR ${ }^{\mathrm{TM}}$ Green Master Mix (Applied Biosystems, Thermo Fisher Scientific) essentially as previously described (Pokorzynski et al., 2020, 2019). In brief, cDNA was diluted 1:5-1:10 and gDNA was diluted 1:50-1:100 in nucleasefree $\mathrm{H}_{2} \mathrm{O}$ (dilutions were identical within each experiment). The 2X PCR master mix was diluted to $1 \mathrm{X}$ in nuclease-free $\mathrm{H}_{2} \mathrm{O}$ with specific primers diluted to $500 \mathrm{nM}$ (see Supplementary Data 2 for complete list of primers). To $79 \mu \mathrm{L}$ of the master mix solution, $3.3 \mu \mathrm{L}$ of template (cDNA or gDNA) was added and then aliquoted into three $25 \mu \mathrm{L}$ technical replicate reactions in a 96-well optical plate. Reactions were analyzed on a QuantStudio ${ }^{\mathrm{TM}} 3$ Real-Time PCR System with standard SYBR cycling conditions. All assays were performed with a melt-curve analysis to ensure specific product amplification across samples. Primer sets (Supplementary File 1) used in qPCR were validated against a standard curve of C. trachomatis L2 gDNA diluted from $2 \times 10^{-3}$ to 2 $\times 10^{\circ} \mathrm{ng}$ per reaction. $\mathrm{C}_{\mathrm{t}}$ values generated from each experimental reaction were then fit to a standard curve and only primer sets with an efficiency of $100 \%+/-5 \%$ were used.

Genome equivalents (GE) were calculated by first converting the mean $C_{t}$ of the triplicate technical replicate reactions to a ng quantity of gDNA (ng template) with the linear equation generated from the standard curve of the euo primer pair. This value was then normalized to the total $\mathrm{ng} / \mu \mathrm{L} \mathrm{gDNA}$ isolated for each sample as follows:

$$
G E=\frac{n g \text { template }}{\frac{n g}{\mu L} g D N A}
$$

For the quantification of transcript expression by reverse transcription (RT)-qPCR, a transcriptome-based normalization was used based on the geometric average of multiple control genes, which were empirically determined using the geNorm method (Vandesompele et al., 2002). For more information on the geNorm analysis, see Supplemental Note 1. In brief, all transcript expression data was normalized to the geometric mean of the expression of groEL_1, euo, $\operatorname{rrd} A$ and $\operatorname{nrdB}$. The $\triangle \Delta \mathrm{Ct}$ method was then used to determine relative expression values and the log2-transformed fold change was analyzed to facilitate comparisons between conditions where the magnitude of gene expression changed considerably (e.g. expression of the trpRBA operon in ironor tryptophan-starved conditions). Thus, transcript expression (TE) was calculated as:

$$
T E=2^{-\left(\left[C t_{E x p}-C t_{\text {geNorm }}\right]-C t_{\text {Ref }}\right)}
$$

Where $C_{t}(\operatorname{Exp})$ is the $C_{t}$ value of the experimental gene being analyzed, $C_{t}(g e N o r m)$ is the geometric mean of the $C_{t}$ values for the control genes, and $\mathrm{C}_{\mathrm{t}}(\mathrm{Ref})$ is the mean $\mathrm{C}_{\mathrm{t}}$ value of the reference condition, in this case UTD24. All $\mathrm{C}_{\mathrm{t}}$ values were corrected for dilution prior to the computation of transcript expression.

\section{Immunofluorescent confocal microscopy}

To analyze inclusion morphology, HeLa cells were seeded onto acid-washed glass coverslips in 24-well tissue culture plates and infected at $\mathrm{MOI}=5$. At the indicated times post-infection, coverslips were washed with phosphate-buffered saline (PBS) and cells were fixed with $4 \%$ paraformaldehyde in PBS for $15 \mathrm{~min}$ at $\mathrm{RT}^{\circ} \mathrm{C}$. Fixation solution was then aspirated and coverslips were either stored at $4^{\circ} \mathrm{C}$ in PBS or immediately processed for immunofluorescence assays by permeabilizing cells in PBS $+0.2 \%$ Triton $\mathrm{X}-100$ (Thermo Scientific ${ }^{\mathrm{TM}}$ ) for $10 \mathrm{~min}$ at $\mathrm{RT}^{\circ} \mathrm{C}$ with rocking. Permeabilization solution was then decanted and coverslips were washed $3 x$ with PBS. Coverslips were blocked in PBS $+3 \%$ bovine serum albumin (BSA) for 1 hr at $\mathrm{RT}^{\circ} \mathrm{C}$ with rocking Coverslips were then washed 3x with PBS prior to being overturned on a $50 \mu \mathrm{L}$ droplet of PBS $+3 \%$ BSA containing primary antibody diluted 1:1000. To detect chlamydial GroEL, cells were stained with monoclonal mouse anti-cHsp60 (MA3-023, Invitrogen, ThermoFisher Scientific). Coverslips were incubated on primary antibody solution overnight at $4^{\circ} \mathrm{C}$ in an opaque humidified container. Coverslips were then washed thoroughly by repeated submersion ( 50x) in $100 \mathrm{~mL}$ PBS before being overturned on a $50 \mu \mathrm{L}$ droplet of PBS $+3 \%$ BSA $+1: 1000$ secondary antibody $+2.5 \mu \mathrm{g} / \mathrm{mL} 44^{\prime}, 6$-diamidino2-phenylindole (DAPI) to label nuclei. A donkey anti-mouse AlexaFluor-594 secondary antibody (Invitrogen, Thermo Fisher Scientific) was used to label the primary mouse anti-cHsp60. Coverslips were then incubated for at least one hour at $\mathrm{RT}^{\circ} \mathrm{C}$ in an opaque humidified container prior to being washed as described above in Milli-Q $\mathrm{H}_{2} \mathrm{O}$ and then being mounted on glass microscope slides with $10 \mu \mathrm{L}$ Shandon ${ }^{\mathrm{TM}}$ Immu-Mount (Thermo Fisher Scientific). Mounting medium was allowed to solidify overnight. Confocal microscopy was performed on a Nikon Ti2 Eclipse spinning-disk confocal microscope. All images were acquired using identical laser power and exposure settings. To enhance visualization of inclusion morphology, contrast and brightness were adjusted as necessary for each condition in Fiji ImageJ (Schindelin et al., 2012). All images are summed Z-projections of Z-stacks spanning the entire depth of the inclusions in the field. 
bioRxiv preprint doi: https://doi.org/10.1101/2021.08.14.456350; this version posted August 15, 2021. The copyright holder for this preprint (which was not certified by peer review) is the author/funder, who has granted bioRxiv a license to display the preprint in perpetuity. It is made available under aCC-BY 4.0 International license.

\section{Reinfection assay}

At the indicated times post-infection for the relevant treatment conditions, infected cells were scraped into cell culture media and collected in $2 \mathrm{~mL}$ microcentrifuge tubes. Cell suspensions were then centrifuged at $21,000 \times \mathrm{xg}$ for $30 \mathrm{~min}$ at $4^{\circ} \mathrm{C}$ to rupture cells. The supernatant was aspirated and the cell pellet was resuspended in $500 \mu \mathrm{L}$ of sterile-filtered Sucrose-phosphate-glutamate (SPG; $220 \mathrm{mM}$ sucrose, $10 \mathrm{mM} \mathrm{Na}_{2} \mathrm{HPO}_{4}, 4$ mM KH $\mathrm{PO}_{4}, 5 \mathrm{mM} \mathrm{Glutamic}$ Acid) buffer. The resuspended cell lysate was centrifuged at $200 \mathrm{xg}$ for $5 \mathrm{~min}$ at $4^{\circ} \mathrm{C}$ to pellet cell debris. The supernatant was stored at $-80^{\circ} \mathrm{C}$ and used to reinfect a confluent HeLa cell monolayer in one well of a 24-well tissue culture plate in a ten-fold dilution series starting at 10 or $100 \mu \mathrm{L}$ of inoculum. At $24 \mathrm{hpi}$, the reinfected cells were fixed and stained as above for DAPI and GroEL and at the appropriate dilution for each condition, inclusions were enumerated per field (total of five fields per replicate) and the number of IFU per $\mathrm{mL}$ of inoculum was calculated. For reactivation, media containing mizoribine was removed at $24 \mathrm{hpi}$ and the samples were incubated with fresh media for an additional 16 hours prior to sample collection. The limit of detection was calculated to be one inclusion identified per field at $100 \mu \mathrm{L}$ of inoculum.

\section{Measurement of intracellular GTP levels}

Infected or mock-infected cells under the indicated treatment conditions were collected at 24 hpi by washing cells in $2 \mathrm{~mL}$ PBS, aspirating the wash buffer, and then scraping the cells into $250 \mu \mathrm{L} 1 \%$ trichloracetic acid (TCA) solution to precipitate macromolecular complexes. The lysate was centrifuged to collect precipitates and the supernatant was neutralized to $\mathrm{pH} \sim 7.5$ with $20 \mu \mathrm{L} 1 \mathrm{M}$ Tris- $\mathrm{HCl}, \mathrm{pH} 8.5$ prior to storage at $-80^{\circ} \mathrm{C}$. Intracellular GTP levels were then measured using the GTPase-Glo assay kit (Promega Corporation, Madison, WI, USA), which was adapted to measure GTP from cell lysates (see Fig. 7A). In brief, $60 \mu \mathrm{L}$ of TCA-precipitated lysate was diluted in $60 \mu \mathrm{L}$ of GTPase/GAP buffer. A $10 \mu \mathrm{M}$ stock solution of rGTP, provided by the manufacturer, was used as a positive control for the assay. Each sample was then aliquoted in quadruplicate $25 \mu \mathrm{L}$ volumes in separate wells of a white polystyrene 96-well plate. Two wells for each sample received GTPase-Glo buffer containing ADP and GTPase-Glo reagent ([ATP]+[GTP]), while the other two wells received GTPase-Glo buffer alone ([ATP]). Samples were then incubated for $30 \mathrm{~min}$ at $\mathrm{RT}^{\circ} \mathrm{C}$ with shaking. Following incubation, $50 \mu \mathrm{L}$ of Detection reagent was added to each well and allowed to incubate for another 10 min at $R T^{\circ} \mathrm{C}$ with shaking. Luminescence was then measured on a Tecan Spark $®$ microplate reader (Tecan Group Ltd., Männedorf, Switzerland). GTP levels were calculated by subtracting the baseline [ATP] luminescence reading from the converted [GTP]+[ATP] luminescence reading. All values were normalized to the mean of the untreated, mock-infected control group.

\section{Statistics}

All statistical computations were performed in RStudio (version 1.3.1093) using base platform functions and the code is available as indicated above. All plots were made in the ggplot2 base package (version 3.1.0) (Wickham, 2009) and the ggpubr package (version 0.2.3; https://CRAN.Rproject.org/package=ggpubr) or in Adobe Illustrator (version 24.1.2). All tests are indicated in the figure legends along with the value of $\mathrm{N}$ (independent biological replicates). All plots represent the mean and standard deviation of the data. Significance was defined as a $p$-value below 0.05 and a sample size of three was considered satisfactory for estimating normality. 


\section{Supplemental Information}

\section{Figure 1 - Supplementary Text}

The validation of RNA-sequencing data for chlamydial transcriptomes is not straight-forward (Ardissone et al., 2020; Brinkworth et al., 2018), primarily owing to the conventional normalization method utilized for targeted RTqPCR gene expression data. Two general means of normalizing RT-qPCR data have been proposed: (1) normalization of gene expression to genome equivalents and (2) normalization of gene expression to the expression of an internal control gene. In the case of the former method, gene expression is interpreted on a per-organism basis, reflecting changes in absolute transcript levels. In the case of the latter method, gene expression is theoretically represented as a proportion of the total transcriptome, but the common practice of normalizing to a single control gene carries many assumptions that are often faulty, such as the turnover rate of the control gene under various conditions, leading to erroneous results (Engström et al., 2010). Yet, the nature of genome normalization can produce unclear results depending on the experimental question being asked. During chlamydial persistence, where genome copies are reduced and basal transcriptional activity increases (Ouellette et al., 2006), genome normalization can over-estimate the up-regulation of genes whose abundance as a proportion of the total transcriptome does not change.

We therefore considered an alternative means of RT-qPCR normalization: geometric averaging of multiple control genes by the geNorm method (Vandesompele et al., 2002). This approach relies on the identification of stably expressed groups of control genes, empirically determined by an assessment of their stability (i.e. the maintenance of the ratio of their raw expression values) and their pairwise variation (i.e. the variation in stability between any two control genes across conditions). The analysis therefore provides a normalization factor that is based on the stable relationship of the expression of multiple control genes, rendering it more insensitive to instability or fluctuations in the expression of a single control gene. We used this method to analyze the following seven transcripts: euo, omcB, groEL_1, ompA, nrdA, nrdB, and 16S rRNA. We determined that across our experimental conditions, euo and gro $E L \_1$ were the most stably associated genes under the tested conditions (Figure 1 - Figure Supplement 1, A and B) and that the set of euo, groEL_1, nrdA and $n r d B$ had the lowest average pairwise variation (Figure 1 - Figure Supplement $1 \mathrm{C}$ ) and were most suitable for the derivation of a normalization factor. We note that while the suggested cut-off for pairwise variation of a set of control genes is 0.15 , we find that all genes analyzed here appear highly stable (with pairwise variation not exceeding 0.027), likely reflecting the strong effect of developmental regulation on the relationship of chlamydial gene expression. This normalization facilitated the confirmation of RNA-sequencing data by RTqPCR by increasing the sensitivity for down-regulated or unchanged gene expression. This normalization also more accurately reflects the normalization methods utilized during RNA-sequencing, i.e. transcriptome-based normalization factors across conditions. We suggest that future gene expression studies in Chlamydia carefully consider the most suitable normalization method for the experimental question at hand. 
bioRxiv preprint doi: https://doi.org/10.1101/2021.08.14.456350; this version posted August 15,2021 . The copyright holder for this preprint (which was not certified by peer review) is the author/funder, who has granted bioRxiv a license to display the preprint in perpetuity. It is made available under aCC-BY 4.0 International license.

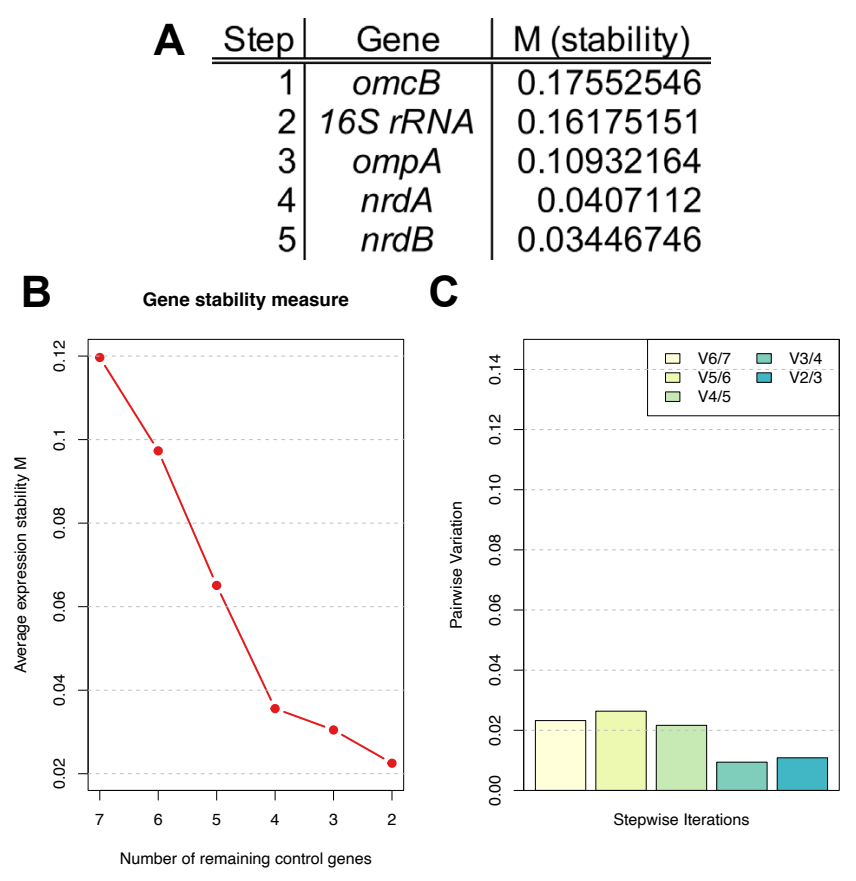

Figure 1 - Figure Supplement 1. Analysis of stable control genes by geNorm. (A) Table displaying the step-wise exclusion of genes with the lowest stability (highest $\mathrm{M}$ value) following geNorm analysis. (B) Plot of average gene stability (M) during the stepwise exclusion of unstable genes. (C) Plot of pairwise variation of remaining control genes during the stepwise exclusion of unstable genes. 
bioRxiv preprint doi: https://doi.org/10.1101/2021.08.14.456350; this version posted August 15,2021 . The copyright holder for this preprint (which was not certified by peer review) is the author/funder, who has granted bioRxiv a license to display the preprint in perpetuity. It is made available under aCC-BY 4.0 International license.
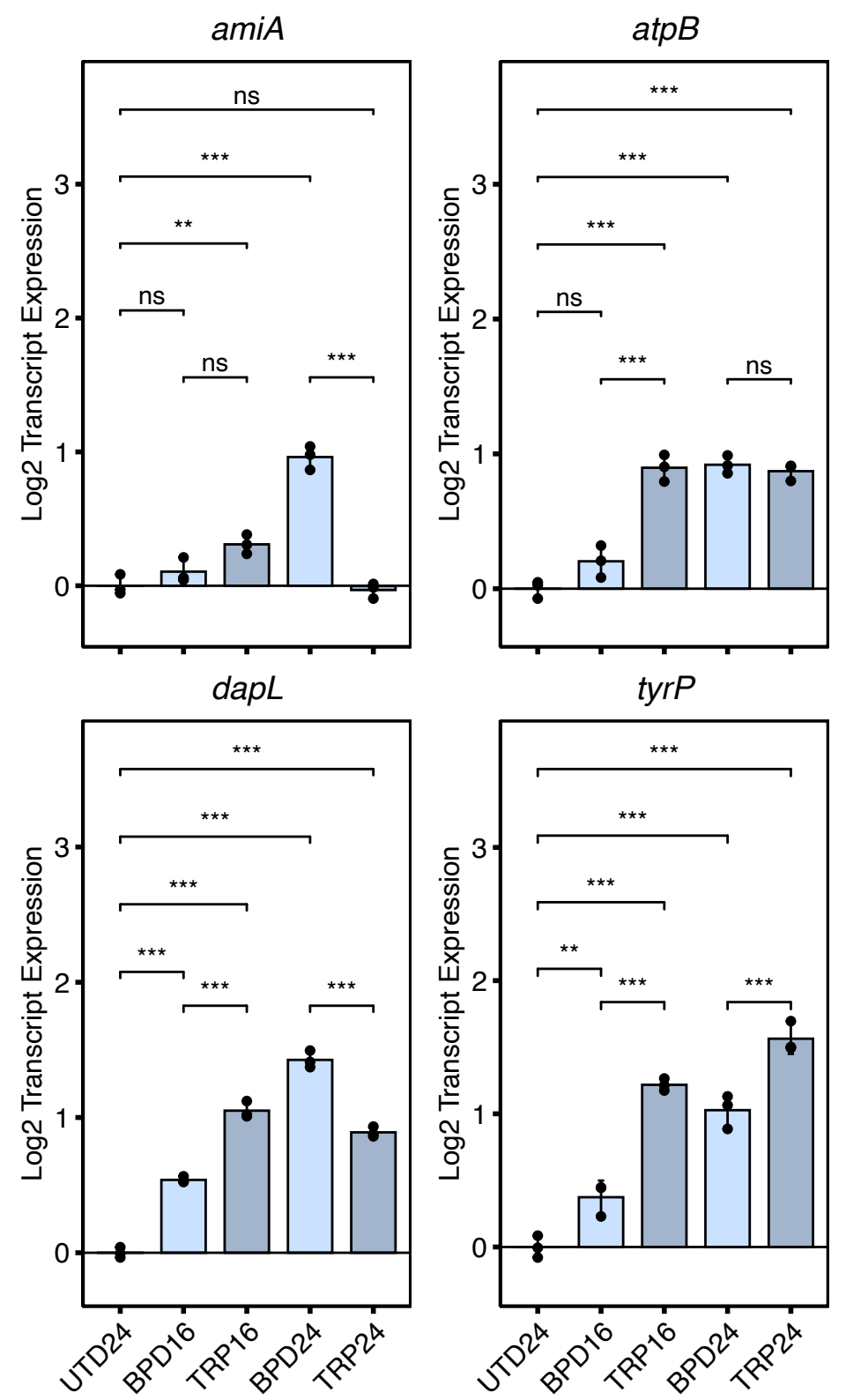

Figure 3 - Figure Supplement 1. Validation of differential expression for selected accessory genes during nutritional stress. All plots represent the mean and standard deviation of three independent biological replicates $(N=3)$. Statistical significance in all panels was determined by one-way ANOVA followed by Tukey's post-hoc test of honestly significant differences (two-tailed). ${ }^{*}=p<0.05,{ }^{* *}=p<$ $0.01,{ }^{* *}=p<0.001, \mathrm{~ns}=$ not significant. 
bioRxiv preprint doi: https://doi.org/10.1101/2021.08.14.456350; this version posted August 15,2021 . The copyright holder for this preprint (which was not certified by peer review) is the author/funder, who has granted bioRxiv a license to display the preprint in perpetuity. It is made available under aCC-BY 4.0 International license.

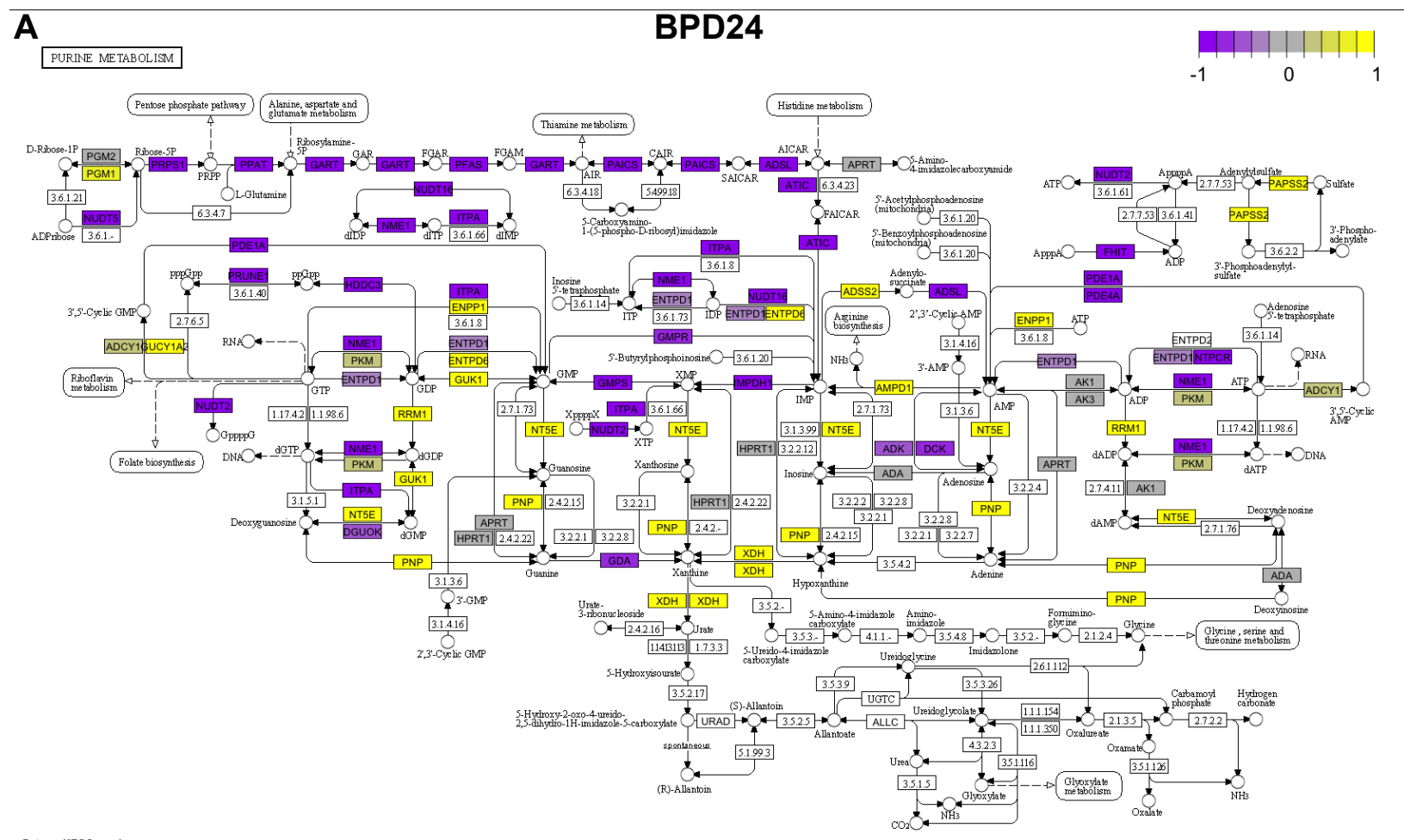

B PURINE ME TABOLISM TRP24

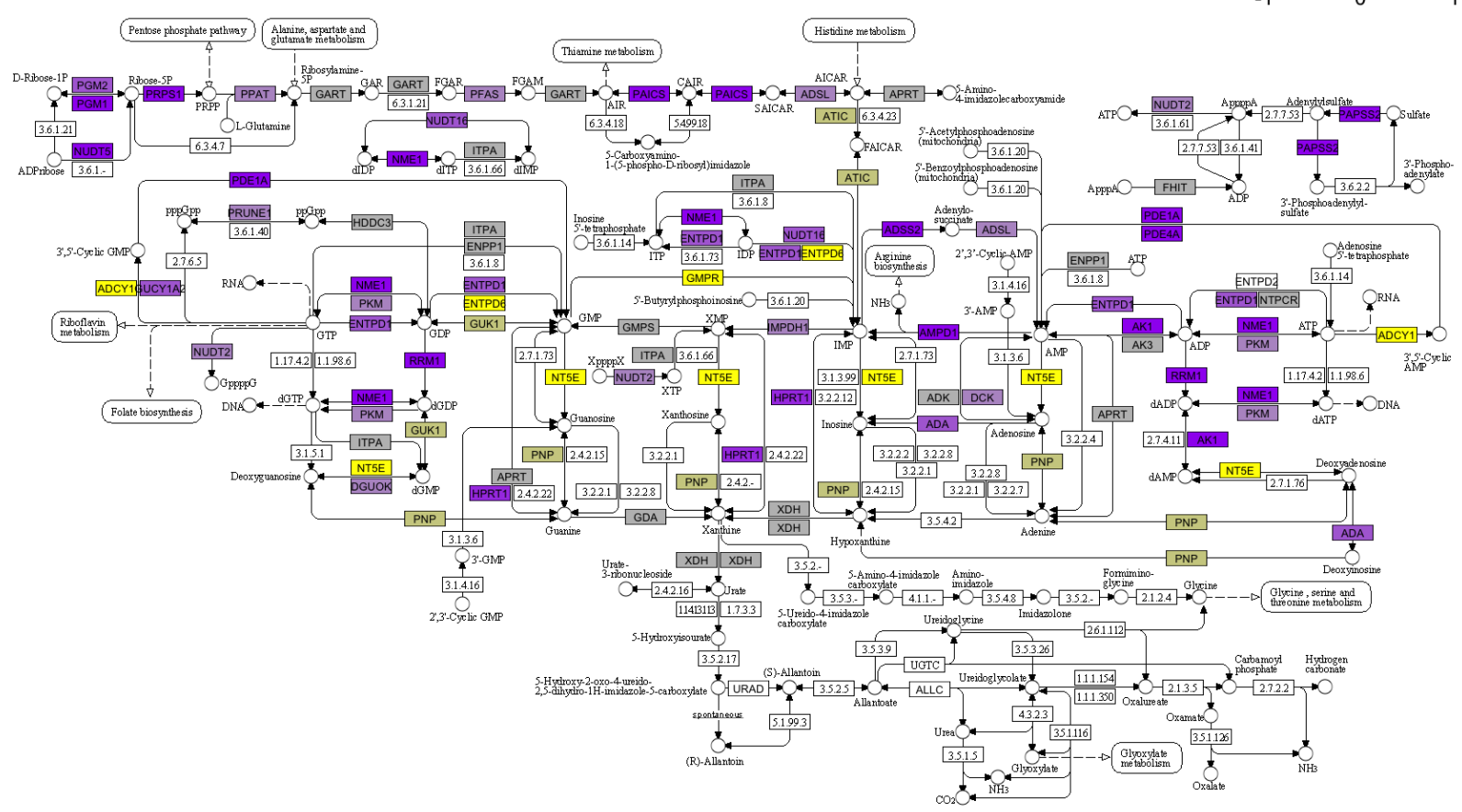

Data on KEGG graph
Rendered by pathview

Figure 5- Figure Supplement 1. Differential expression of genes in the purine metabolism pathway of persistently-infected HeLa cells. (A) Pathway data for BPD24 extracted by Pathview. (B) Pathway data for TRP24 extracted by Pathview. 
bioRxiv preprint doi: https://doi.org/10.1101/2021.08.14.456350; this version posted August 15, 2021. The copyright holder for this preprint (which was not certified by peer review) is the author/funder, who has granted bioRxiv a license to display the preprint in perpetuity. It is made available under aCC-BY 4.0 International license.

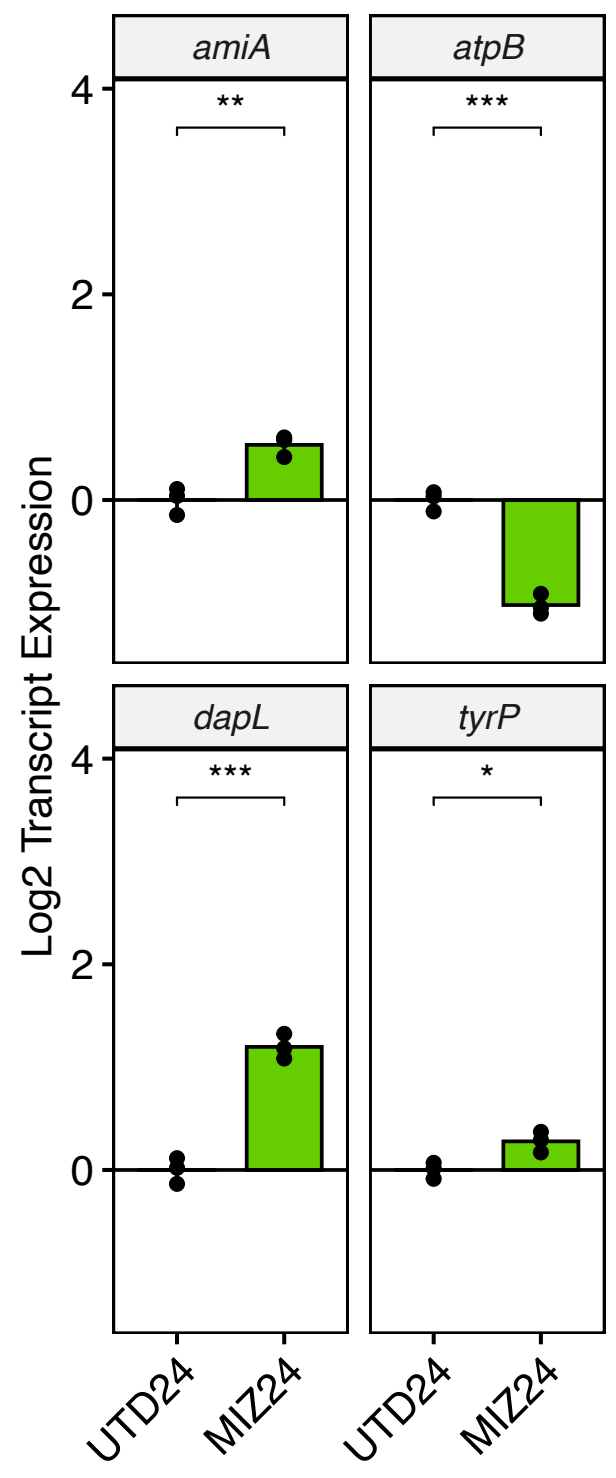

Figure 6 - Figure Supplement 1. Analysis of accessory gene expression in MIZ24. Statistical significance in all panels was determined by pairwise two-sided unpaired Welch's $t$-test for unequal variance. ${ }^{*}=p<0.05,{ }^{* *}=p<0.01,{ }^{* * *}=p<0.001$. All plots represent the mean and standard deviation of three independent biological replicates $(\mathrm{N}=3)$. 

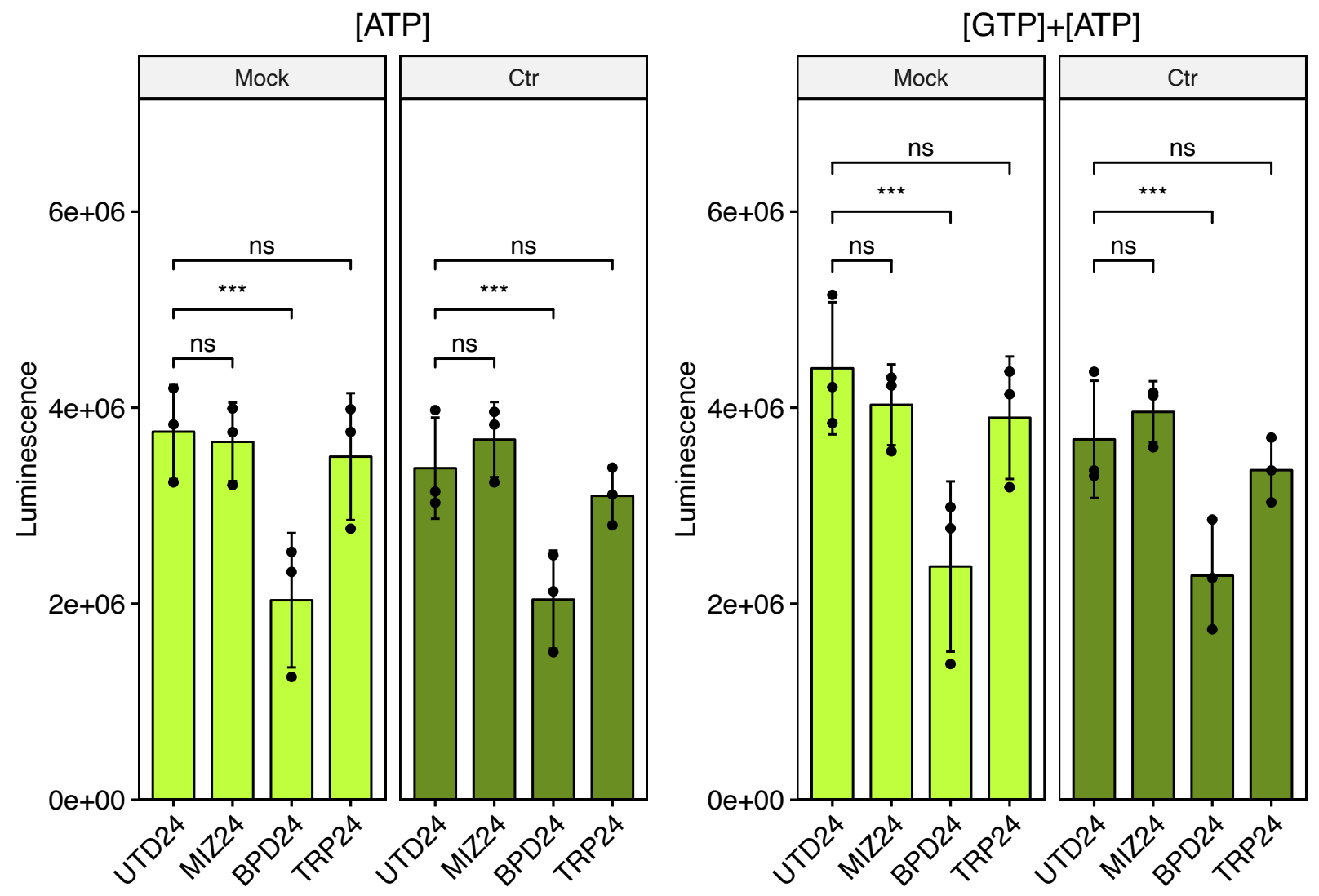

Figure 7 - Figure Supplement 1. Total luminescent output in unconverted ([ATP]) and converted ([GTP]+[ATP]) reactions for the measurement of intracellular GTP levels. Note that the values in ([GTP]+[ATP]) samples are higher than those in [ATP] alone, reflecting the conversion of the GTP pool. All plots represent the mean and standard deviation of three independent biological replicates $(\mathrm{N}=3)$. Statistical significance in all panels was determined by one-way ANOVA followed by Tukey's post-hoc test of honestly significant differences (two-tailed). ${ }^{*}=p<0.05,{ }^{* *}=p<0.01,{ }^{* * *}=p<0.001, \mathrm{~ns}=$ not significant. 